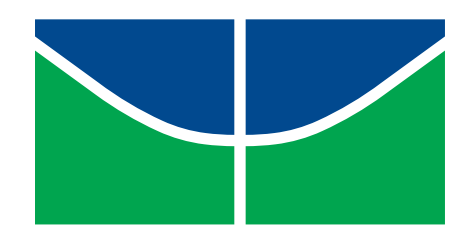

\author{
Universidade de Brasília \\ Instituto de Ciências Exatas \\ Departamento de Matemática
}

Problemas de máximos e mínimos: Abordagem na Educação Básica

$$
\text { por }
$$

Fabiano Rodrigues Marcolino

Brasília, 2016 
Fabiano Rodrigues Marcolino

\title{
Problemas de máximos e mínimos: Abordagem na Educação Básica
}

\author{
Dissertação apresentada como parte dos requisitos \\ para a obtenção do título de Mestre junto ao Pro- \\ grama de Pós-Graduação em Matemática Profissi- \\ onal em Rede Nacional - PROFMAT, do Departa- \\ mento de Matemática da Universidade de Brasília.
}

Orientador: Prof. Dr. Hélder de Carvalho Matos

Brasilia

2016 
Ficha catalográfica elaborada automaticamente, com os dados fornecidos pelo(a) autor(a)

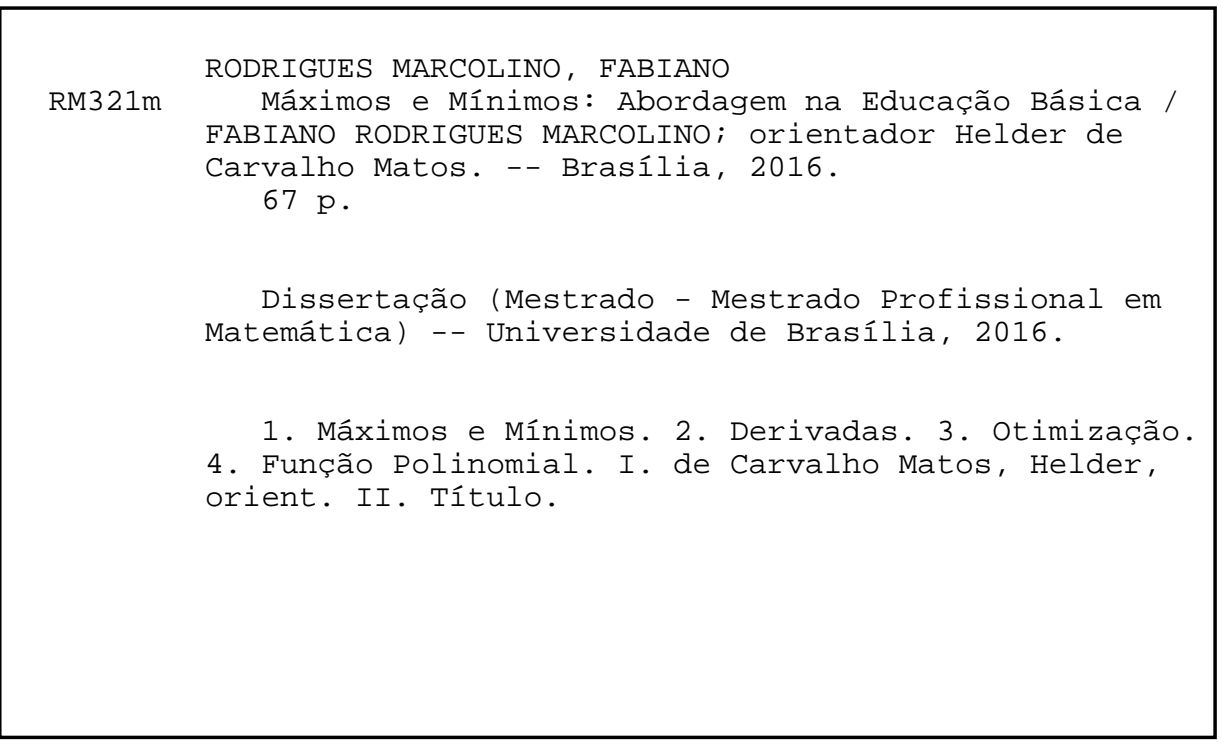


Todos os direitos reservados. Proibida a reprodução total ou parcial desse trabalho sem a autorização da Universidade, do autor e do orientador.

Fabiano Rodrigues Marcolino graduou-se em Licenciatura em Matemática pela Universidade de Brasília no ano de 2002; Concluiu o curso de Pós-Graduação Lato Sensu em Coordenação e Supervisão Pedagógica pelo Instituto Darwin em 2010. Atualmente atua como professor e coordenador pedagógico na Secretaria de Estado de Educação do Distrito Federal. 


\section{DEDICATÓRIA}

Dedico esse trabalho ao meu pai, Luiz Fernando Marcolino. 
"Teu nome e tuas glórias têm honra e resplendor"

Tenente Porphirio Da Paz 


\section{Agradecimentos}

À minha querida mãe, Sylvia, por tudo que já fez e ainda fará por mim, sempre com a melhor das intenções.

Às minhas famílias, sanguíneas ou não, pois tenho orgulho de ter pessoas tão valiosas na minha vida que, mesmo que não haja relação de parentesco, não consigo me referir a eles como algo menos que irmãos.

À preciosa contribuição técnica dos amigos José Oniram e Salomão Diniz.

Ao Prof. Dr. Helder, meu orientador, pela compreensão e pela brilhante colaboração para o desenvolvimento dessa dissertação.

Aos professores do Departamento de Matemática da Universidade de Brasília, em especial ao Prof. Dr. Rui Seimetz, que com seus valiosos ensinamentos, me fizeram recordar do orgulho de ter me graduado nessa instituição.

Aos amigos e amigas do PROFMAT pelas inúmeras contribuições, não apenas no ambiente acadêmico, mas sim para a vida de modo geral. Em especial ao amigo André Luis Pontes Pavoni, parceiro de longa data nessa jornada.

Agradeço à Coordenação de Aperfeiçoamento de Pessoal de Nível Superior - CAPES pelo suporte financeiro durante todo o curso e o desenvolvimento desse trabalho.

À Secretaria de Educação do Distrito Federal por conceder o afastamento para estudos. Concessão essa que foi primordial para o melhor aproveitamento da minha parte das disciplinas do curso, propiciando assim grande enriquecimento para o meu desenvolvimento profissional.

Aos alunos, professores e direção do Centro Educacional 619 de Samambaia que forneceram um imenso auxílio nessa produção.

Agradeço enfim, a todos aqueles que, independente da forma ou da intensidade, me auxiliaram durante todo o andamento do Mestrado. 


\section{Resumo}

O objetivo desse trabalho é aprofundar o estudo de máximos e mínimos e sua abordagem na educação básica, ampliando o espectro das possibilidades de discussão e ensino do tema. A abordagem se dá ao introduzirmos o uso de derivadas e, além disso, obviamente, tratar sobre os conceitos de vértice, pontos de máximos e mínimos, pontos críticos e concavidade dos gráficos para auxiliar a resolução de problemas tradicionais de otimização, envolvendo não somente funções polinomiais do $2^{\circ}$ grau.

Palavras-chave: Máximos, Mínimos, Derivadas, Otimização, Função Polinomial do $2^{\circ}$ grau, Resolução de problemas. 


\begin{abstract}
The aim of this work is to deepen the study of maximum and minimum and its approach to basic education, broadening the spectrum of discussion possibilities and teaching the theme. The approach is given to introduce the use of derivatives and, in addition, obviously, handle on the vertex concepts, points of maximum and minimum, critical points and curvature of the graphs to assist the resolution of traditional optimization problems involving not only functions polynomial of the 2 nd degree.
\end{abstract}

Palavras-chave: Maximum, Minimum, Derivatives, optimization, polynomial function of the 2nd degree, resolution of mathematical problems. 


\section{Sumário}

$\begin{array}{ll}\text { Introdução } & 1\end{array}$

1 Funções 3

1.1 Introdução . . . . . . . . . . . . . . . . . . . . . 3

1.2 Funções injetivas, sobrejetivas e bijetivas . . . . . . . . . . . . 5

1.3 Gráfico de uma função . . . . . . . . . . . . . . . . . . . . . . . . . . . 6

1.4 Domínio e imagem através do gráfico . . . . . . . . . . . . . 6

1.4.1 Crescimento e decrescimento . . . . . . . . . . . . . 8

1.5 Função composta e função inversa . . . . . . . . . . . . . . . . . . . . . 9

1.5.1 Função composta . . . . . . . . . . . . . . . . . . . . . . . . . . . . . . . . .

1.6 Função inversa . . . . . . . . . . . . . . . . . . . . . . . . . 12

2 O Estudo dos Pontos de Máximo e Mínimo de uma Função Quadrática no Ensino Médio 14

3 Derivadas $\quad 16$

3.1 História das Derivadas . . . . . . . . . . . . . . . . . 16

3.2 Conceitos Básicos: Limites e Derivadas . . . . . . . . . . . . . . 17

3.2 .1 Noções de Limites . . . . . . . . . . . . . . . . . . . . . . . . . . . . . . . . . . . . . . . . . .

3.2 .2 O Problema da Reta Tangente . . . . . . . . . . . . . . . . . 19

3.2 .3 Definição de Derivada . . . . . . . . . . . . . . . . . . . 21

3.2.4 Regras de Derivação . . . . . . . . . . . . . . . . . . . . . 21

3.2.5 Derivadas de Funções Elementares . . . . . . . . . . . . . . . . 22

3.2.6 Intervalos de Crescimento e Decrescimento . . . . . . . . . . . 22

3.2 .7 Máximos e Mínimos . . . . . . . . . . . . . . . . . . . . . . . 23

3.2 .8 Teste da primeira derivada . . . . . . . . . . . . . . 24

3.2 .9 Teste da segunda derivada . . . . . . . . . . . . . 24 
4 Máximos e Mínimos de Funções Contínuas

4.1 Existência de Valores Máximos e Mínimos de Funções Contínuas de Uma Variável Real . . . . . . . . . . . . . . . . . . . . . . 27

5 Funções Quadráticas $\quad 33$

5.1 Aplicações . . . . . . . . . . . . . . . . . . . . . . . 34

6 Problemas de Otimização que Recaem em uma Função Quadrática 36

7 Problemas de Otimização Resolvidos com o Uso de Derivadas 44

Referências Bibliográficas $\quad 52$ 


\section{Lista de Figuras}

1.1 Na porção esquerda temos o gráfico de uma função $f: A \rightarrow B$. À direita, um subconjunto de $A \times B$ que não pode ser gráfico de uma função de $A$

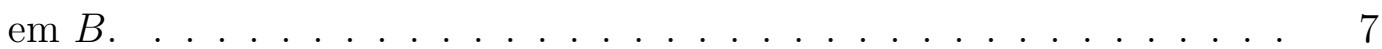

1.2 Gráfico de uma função $f$ para observar o domínio e a imagem. . . . . . 7

1.3 Gráfico de uma função $f$ para determinar o domínio e a imagem. . . . 8

1.4 Gráfico da função $h: \mathbb{R} \rightarrow \mathbb{R}$, crescente em um determinado intervalo e decrescente em outro. . . . . . . . . . . . . . . . . 99 9

1.5 Gráfico que ilustra a composição de duas funções. . . . . . . . . . . . . . 10

3.1 Gráfico de $f(x)=\frac{4 x^{2}-8 x}{x-2} \ldots \ldots \ldots \ldots \ldots$. . . . . . . . . . . . . . . . . . . . 17

3.2 Gráfico de $f(x)=4 x$, com $x$ tendendo a $2 \ldots \ldots \ldots$

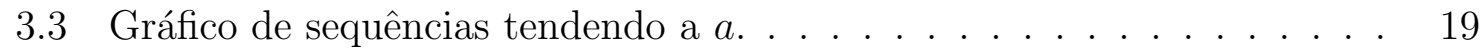

3.4 Reta secante a uma curva . . . . . . . . . . . . . . . . . . 20

3.5 Gráfico com algumas retas secantes e uma tangente . . . . . . . . . . . 20

3.6 Gráfico ilustrando o crescimento e o decrescimento da função $f(x)=$

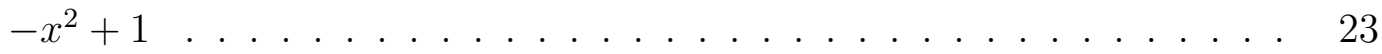

3.7 exemplo de $3.1 \ldots \ldots \ldots \ldots$

5.1 Retângulo de lados x e y . . . . . . . . . . . . . . . . . . . . . . . 34

5.2 Retângulo Inscrito . . . . . . . . . . . . . . . . . . . . . . . 34

6.1 Figura ilustrando a situação apresentada no problema 6.1. . . . . . . 36

6.2 Figura ilustrando a situação apresentada no problema 2. . . . . . . . . 37

6.3 Figura ilustrando a situação apresentada no problema 6.2 (i). . . . . . . 38

6.4 Figura ilustrando a situação apresentada no problema 2 (ii). . . . . . . . 38

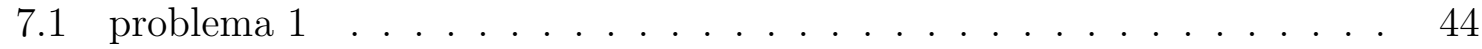

7.2 Figura ilustrando a situação apresentada no Problema. . . . . . . . . . 46 


\section{Introdução}

Faz parte do senso comum considerar a Matemática a mais difícil das disciplinas. Para a maioria daqueles que afirmam isso, a formação dessa opinião se dá pelo fato do ensino dos conteúdos ser acumulativo, fazendo com que temas abordados em séries iniciais voltem a ser discutidos, de modo mais aprofundado, em séries mais avançadas. Também contribui para isso o fato de que não se desperta o quanto antes os hábitos de investigação, leitura e, sobretudo, o pensamento lógico-matemático. O que se vê na maioria dos casos é que os professores não instigam os alunos a buscar soluções, mas apenas ensinam a resolver questões que já foram resolvidas, usando apenas princípios.

Desde os primórdios, o homem já fazia uso de conceitos matemáticos, mesmo que intuitivamente, seja na caça, na pesca, entre outras atividades. As constantes mudanças que ocorrem na sociedade e no próprio indivíduo fizeram com que a Matemática viesse sendo incluída gradativamente na vida dos homens e transformada em funções das necessidades de sobrevivência no meio social.

Ao longo da história, a obtenção de valores máximos ou mínimos para áreas de regiões planas ou volume de sólidos é um dos problemas que mais fascinaram e desafiaram. Questões elementares como "Qual o paralelepípedo reto retângulo, de área total constante, tem o maior volume", cuja solução pode ser encontrada com cálculos elementares, leva-nos a investigar e geram uma significativa quantidade de problemas que podem ser resolvidos através da utilização de desigualdades, por exemplo.

O que se vê na educação básica é que são dadas pouquíssimas oportunidades de contato dos alunos com problemas envolvendo desigualdades e otimização. Com exceção feita ao estudo de Funções Quadráticas, no $1^{\circ}$ ano do Ensino Médio, é praticamente nula a abordagem de problemas de máximos e mínimos no ensino básico, o que é de se lamentar pois claramente o tema poderia ser melhor explorado e assim, despertar nos alunos mais atenção aos conceitos da lógica-matemática e a percepção de que situações de desigualdade podem ser tão, ou mais, importantes que as igualdades. Como o estudo das derivadas só se dá no nível superior de ensino, no ensino básico, os alunos não têm conhecimento suficiente para usarem métodos analíticos na resolução de problemas de 
otimização. O ideal é tratar desses problemas utilizando os conhecimentos da educação básica para fazer com que o cálculo de uma função do $2^{\circ}$ grau tenha mais sentido e não se resuma a apenas encontras as coordenadas do vértice de uma parábola.

Métodos clássicos deram origem aos estudos de otimização e estes, originaram o cálculo diferencial. A existência dos métodos de otimização pode ser atribuída a estudiosos como Lagrange, Cauchy e Newton. Este último, junto de Leibniz, deu imensa contribuição ao desenvolverem métodos de cálculo diferencial e de otimização. Outros nomes como Euler, Bernoulli e Weierstrass também contribuíram de forma extremamente valiosas para o avanço nas técnicas de otimização. Avanço esse que se deu de forma bem lenta até o advento dos computadores digitais na segunda metade do século XX. Esses equipamentos foram evoluindo, ganhando velocidade de processamento, fornecendo assim um grande avanço na pesquisa de novas técnicas.

Com a percepção de que os problemas de máximos e mínimos estão presentes em várias situações, questões pertinentes passaram a ser levantadas: Quando o homem começou a estudar máximos e mínimos? Quais são as teorias usadas na resolução de tais problemas? O porquê de estudar máximos e mínimos? Evidentemente é mais fácil responder à terceira questão, em relação às outras duas, mas esperamos que ao final desse trabalho, todas essas questões sejam resolvidas de maneira satisfatória. 


\section{Capítulo 1}

\section{Funções}

\subsection{Introdução}

O objetivo desse capítulo é revisar brevemente as ideias e conceitos fundamentais de função. Será apresentado o conceito e elementos que compõem uma função.

Definição 1.1 Dados dois conjuntos $X$ e $Y$, uma função de $X$ em $Y$, representada por $f: X \rightarrow Y$ é uma relação que associa cada elemento de $X$ a um, e somente um, elemento de $Y$. Chamamos de $x$ os elementos de $X$ e de $y=f(x)$ os elementos de $Y$.

Dizemos que o conjunto X é o domínio e o conjunto Y é o contradomínio da função $f$. Para todo $x \in X$, dizemos que $y=f(x)$ é o valor assumido por $f$ no ponto $x$ ou a imagem de $x$ pela função $f$. Escreve-se $x \mapsto f(x)$ indicando que $f$ associa $x$ em $f(x)$.

Definição 1.2 Considerando a função $f: X \mapsto Y$, chamamos de imagem de $f$, $(\operatorname{Im}(f))$, o subconjunto de $Y$ dos valores assumidos pela função $f$. Em outra representação, $\operatorname{Im}(f)=f(x): x \in X$.

Deve-se observar que $f(x)$ é a imagem do elemento $x \in X$ pela função f. É corriqueiro encontrar em livros a expressão "a função $f(x)$ " quando o correto é "a função $f$ ". É compreensível que a linguagem incorreta torne a comunicação mais rápida, mas é indispensável que se tenha a noção do que se está fazendo. Em algumas funções como sen $: \mathbb{R} \rightarrow \mathbb{R}$ e $\log : \mathbb{R}_{+} \rightarrow \mathbb{R}$ é fácil utilizar a terminologia correta, deixando as notações $\operatorname{sen}(x)$ e $\log (x)$ para os números reais que representam os valores destas funções num dado ponto $x$. Porém, quando se trata de uma função polinomial, é mais fácil dizer "a função $x^{2}-3 x+2$ " quando a forma correta seria "a função $p: \mathbb{R} \rightarrow \mathbb{R}$ tal que $p(x)=x^{2}-3 x+2$ para todo $x \in \mathbb{R}$ ". O mesmo ocorre com a função exponencial $e^{x}$, a qual tem se tornado mais frequente ser escrita por $\exp (x)=e^{x}$ e assim, ser dita como a função exp $: \mathbb{R} \rightarrow \mathbb{R}$.

Observação 1.1 É importante frisar que uma função é um conceito matemático que contém três parâmetros: 
$1^{\circ}$ Um conjunto onde a função está definida, que é chamado domínio da função.

$2^{\circ}$ O conjunto onde a função toma seus valores, que é chamado de contra-domínio.

$3^{\circ}$ Um algoritmo que permite a cada elemento do domínio associar um único elemento no contra-domínio.

Diante do exposto anteriormente, temos que duas funções $f: X \rightarrow Y$ e $g: X^{\prime} \rightarrow Y^{\prime}$, são iguais se, e somente se, $X=X^{\prime} ; Y=Y^{\prime}$ e $f(x)=g(x)$ para todo $x \in X$.

Quando dizemos simplesmente "a função f", ficam subentendidos seu domínio $X$ e seu contra-domínio $Y$, mas, sem que eles sejam explicitados, a função não existe. Desse modo, quando perguntamos "Qual é o domínio da função $f(x)=\frac{1}{x}$ ?", rigorosamente falando, essa pergunta não faz sentido. A pergunta correta seria: "Qual é o maior subconjunto $X \subset \mathbb{R}$ tal que $f(x)=\frac{1}{x}$ define uma função $f: \mathbb{R} \rightarrow \mathbb{R}$ ?".

Notamos que a pergunta incorreta é mais simples de formular. Por exemplo, podemos definir o volume de uma esfera como uma função do seu raio pela fórmula: $V(r)=\frac{4}{3} \pi r^{3}$. Esta fórmula está definida para todos os números reais, mas a função volume não está definida para valores negativos de $r$. Assim se a intenção é estudar o volume deve-se restringir o domínio para todo $r \geqslant 0$.

A seguir, mais alguns exemplos de funções:

Exemplo 1.1 Considerando $X$ como sendo o conjunto de todos os hexágonos do plano $\pi$ e $\mathbb{R}$ o conjunto dos números reais. Se a cada $h \in X$, fizermos corresponder o número real $f(h)=$ ao perímetro do hexágono $h$, obteremos uma função $f: X \rightarrow \mathbb{R}$.

Exemplo 1.2 Considerando $C$ o conjunto de todas as circunferências do plano $\pi$ e $\mathbb{R}$ $o$ conjunto dos números reais. Se a cada $c \in C$, fizermos corresponder o número real $s(c)=a$ área da circunferência $c$, obteremos uma função $s: C \rightarrow \mathbb{R}$.

Exemplo 1.3 A correspondência que associa, a cada número natural $n$, o seu triplo $3 n$, define uma função $t: \mathbb{N} \rightarrow \mathbb{N}$, com $t(n)=3 n$.

Observação 1.2 Nessa dissertação vamos trabalhar com funções cujos dominios são subconjuntos de $\mathbb{R}$ e cujos contradomínios são todos iguais a $\mathbb{R}$. Como exemplo, observaremos as seguintes regras e, assim, estabeleceremos as condições necessárias para que tais regras sejam funções definidas em um subconjunto $D \subset \mathbb{R}$ e tomando valores em $\mathbb{R}$.

a) $f(x)=\sqrt{x+7}$. Note que a expressão na parte interna do radical não pode ser negativa. Então, como devemos ter $x+7 \geq 0$, então $x \geq-7$. Logo, o domínio de $f$ é $D=[-7 ;+\infty[$.

b) $g(x)=\frac{\sqrt{x}}{x-2}$. Nesse caso, a variável $x$ não pode ser negativa, pois está dentro do radical. Portanto, $x \geq 0$. Mas também sabe-se que o denominador de uma fração não pode ser zero. Portanto, $x \neq 2$. O dominio de g é o intervalo $[0 ;+\infty[$ com exceção feita ao número 2. Sendo assim, podemos escrever o domínio como a união de dois intervalos: $D=[0 ; 2[\cup] 2 ;+\infty[$. 
c) $A(s)=\frac{3 \sqrt{3}}{2 s^{2}}$, onde $A(s)$ é a área de um hexágono regular, cujo lado tem comprimento s. Reparamos que a expressão algébrica tem restrição e assim, tem como dominio todos os números reais exceto $s=0$. Mas, pelo que a função representa, o valor s não pode ser negativo. Então, o domínio de A é o intervalo $D=] 0 ;+\infty[$.

\subsection{Funções injetivas, sobrejetivas e bijetivas}

A seguir, definiremos as classificações das funções como injetivas, sobrejetivas e bijetivas .

Definição 1.3 Uma função $f: X \rightarrow Y$ é injetiva quando diferentes elementos de $X$ são transportados por $f$ em elementos diferentes em $Y$. Ou seja, $f$ é injetiva quando $x_{1} \neq x_{2}$ em $X$ então $f\left(x_{1}\right) \neq f\left(x_{2}\right)$.

Esta condição pode também ser escrita na sua forma contra positiva: $f\left(x_{1}\right)=$ $f\left(x_{2}\right) \rightarrow x_{1}=x_{2}$.

A função $t: \mathbb{N} \rightarrow \mathbb{N}$ que associa a cada número natural $n$ seu triplo $3 n$ é um exemplo de função injetiva. Já a função $f: X \rightarrow \mathbb{R}$ que associa a cada triângulo o seu perímetro, não é uma função injetiva, pois podemos ter distintos triângulos com o mesmo perímetro.

Definição 1.4 Uma função $f: X \rightarrow Y$ chama-se sobrejetiva quando, para qualquer elemento $y \in Y$, é associado ao menos um elemento $x \in X$ tal que $f(x)=y$.

A função $d: \mathbb{N} \rightarrow \mathbb{N}$ que associa a cada número natural n seu triplo $3 n$ não é um exemplo de função sobrejetiva, pois, por exemplo, o número natural 2 não é o triplo de nenhum $n \in \mathbb{N}$. Do mesmo modo a função $s: \mathbb{R} \rightarrow \mathbb{R}$ que associa a cada circunferência do plano $\pi$ sua área, não é uma função sobrejetora, pois um número real negativo não é área de nenhuma circunferência de $\pi$. Já a função $m: S \rightarrow \Delta$ que associa sua mediatriz $m(A B)$ a cada segmento de reta $A B \in S$, onde $S$ é o conjunto dos segmentos de reta do plano $\pi$ e $\Delta$ o conjunto das retas desse mesmo plano, é uma função sobrejetiva, pois toda reta do plano é mediatriz de algum segmento.

Observação 1.3 Sempre que uma função $f: X \rightarrow Y$ tenha o seu contradomínio $Y$ igual ao conjunto imagem $\operatorname{Im}(f)$, dizemos que a função $f$ é sobrejetiva.

Definição 1.5 Dizemos que uma função $f: X \rightarrow Y$ é uma correspondência biunívoca entre $X$ e $Y$ quando é injetiva e sobrejetiva ao mesmo tempo. Nesse caso, dizemos que a função é bijetiva.

Para ilustrar de forma mais eficaz este conceito, forneceremos alguns exemplos:

Exemplo 1.4 Sejam $X=\{1 ; 2 ; 3 ; 4 ; 5\}$ e $Y=\{1 ; 8 ; 27 ; 64 ; 125\}$. Definindo $f: X \rightarrow$ $Y$ pela regra $f(n)=n^{3}$, temos uma correspondência biunívoca, onde $f(1)=1, f(2)=$ $8, f(3)=27, f(4)=64$ e $f(5)=125$. 
Exemplo 1.5 Um exemplo extremamente elementar de uma função bijetiva é a função identidade $f: \mathbb{R} \rightarrow \mathbb{R}$, definida por $f(x)=x$, para todo $x \in \mathbb{R}$.

Exemplo 1.6 Um exemplo de correspondência biunívoca, descoberto pelo físico Galileu Galilei(1564 - 1642). Considerando o conjunto dos números naturais pares $P=$ $2 ; 4 ; 6 ; 8 ; \ldots$, obtém-se uma correspondência biunívoca $p: \mathbb{N} \rightarrow \mathbb{P}$, onde $p(n)=2 n$ para todo $n \in \mathbb{N}$. O interessante é que $\mathbb{P}$ é subconjunto próprio de $\mathbb{N}$.

Exemplo 1.7 Observando os conjuntos $X=\{1\}$ e $Y=\{0 ; 1\}$ conclui-se ser evidente que não pode existir uma correspondência biunívoca $f: X \rightarrow Y$. Portanto, $f: X \rightarrow Y$ não é bijetiva.

\subsection{Gráfico de uma função}

A partir do gráfico da função podemos extrair uma série de informações a respeito do comportamento das funções (ou situações) que ele representa. Por meio dele, podemos ter uma visão do crescimento ou decrescimento da função, dos valores máximos e/ou mínimos que ela assume, das simetrias, do comportamento para valores x, sejam eles muito grandes ou pequenos, etc.

Definição 1.6 O gráfico cartesiano de uma função $f: X \rightarrow Y$ é o conjunto dos pontos $(x ; y)$ do plano que satisfazem a condição, $x \in X$ e $y=f(x) \in Y$. Ou seja, o conjunto de todos os pontos da forma $(x ; f(x))$ do plano, com $x$ variando no domínio de $f$.

$$
G(f)=(x ; y) \in X \times Y: y=f(x) \subset X \times Y
$$

De outro modo, dizemos que o gráfico de uma função é o lugar geométrico dos pontos que satisfazem sua lei de associação. Os gráficos permitem representar geometricamente as funções e assim facilitar a compreensão de algumas de suas principais características. Por exemplo, podemos através de um gráfico verificar se uma dada relação é ou não uma função. Para que um subconjunto $G \subset A \times B$ seja o gráfico de uma função $f: A \rightarrow B$, é necessário e suficiente que, para cada $x \in A$, exista um único ponto $(x ; y) \in G$ cuja primeira coordenada seja $x$. Para funções $f: A \in B$, onde $A$ e $B$ são conjuntos de números reais, esta condição significa que toda paralela ao eixo das ordenadas, traçada por um ponto de $A$ deve cortar o gráfico $G$ num e num só ponto (figura 1.1).

\subsection{Domínio e imagem através do gráfico}

É comum encontrarmos exercícios em livros do ensino médio cujos enunciados pedem para determinar o domínio de funções com expressões algébricas dadas. Como citamos anteriormente, uma função possui três elementos: domínio, contradomínio e 

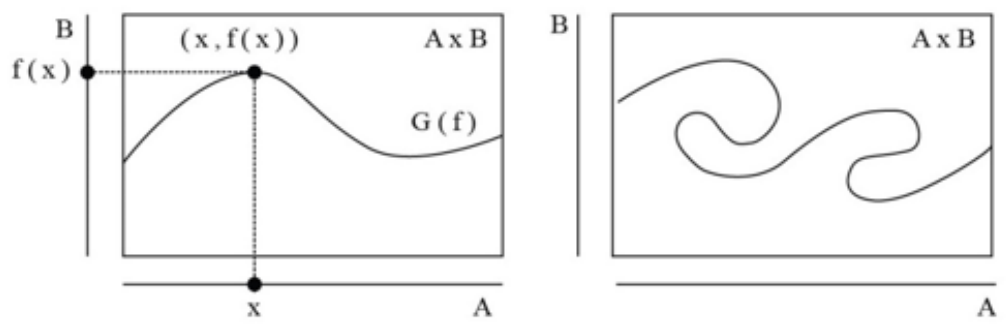

Figura 1.1: Na porção esquerda temos o gráfico de uma função $f: A \rightarrow B$. À direita, um subconjunto de $A \times B$ que não pode ser gráfico de uma função de $A$ em $B$.

lei de associação. Quando é dito que se conhece a função, então seu domínio já deve ser sabido. Portanto, não faz sentido solicitar que se determine o domínio de uma função dada. A intenção de exercícios deste tipo é pedir que se determine o maior subconjunto de $\mathbb{R}$ possível que pode ser definido como domínio de uma função onde a expressão algébrica dada estabelece a lei de associação.

No entanto, se o gráfico da função já for conhecido, podemos obter facilmente o seu domínio e assim como sua imagem. Considere o gráfico da figura 1.2 e observe que podemos identificar o domínio e a imagem da função através do seu gráfico. Observe, como forma de exemplo, o gráfico da figura 1:3 de uma função $f: D \subset \mathbb{R} \rightarrow \mathbb{R}$.

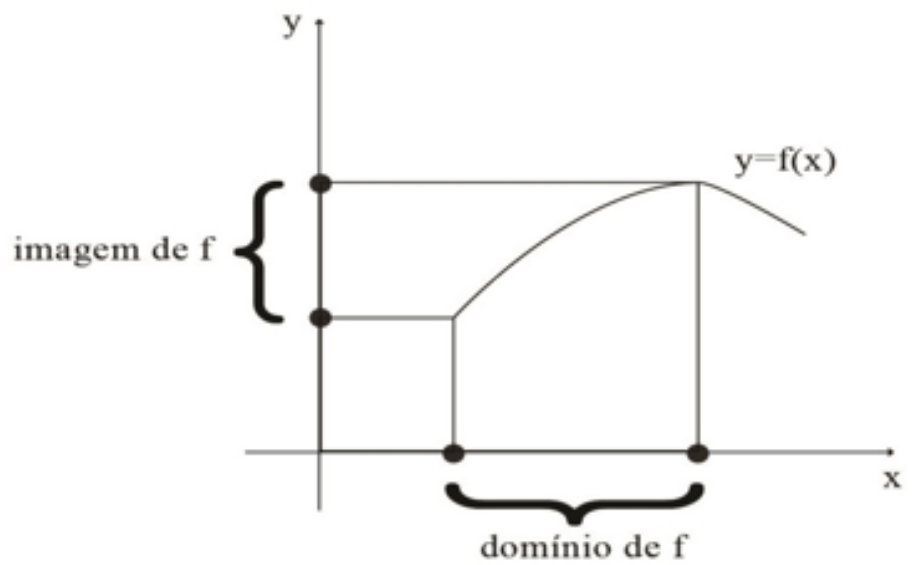

Figura 1.2: Gráfico de uma função $f$ para observar o domínio e a imagem.

Ao traçar retas perpendiculares ao eixo $\mathrm{x}$, de cada ponto do gráfico de $\mathrm{f}$, as intersecções dessas retas com o eixo $x$ nos dá um subconjunto de $\mathbb{R}$. Esse intervalo é o domínio $D$ da função $f$ que pode ser expresso como: $D(f)=x \in R:-3 \leqslant x \leqslant 4$. Utilizando raciocínio análogo, ao traçar, por cada ponto do gráfico de $f$, retas perpendiculares ao eixo $y$, as intersecções dessas retas com o eixo y nos dá um subconjunto de $\mathbb{R}$. Esse intervalo é o conjunto imagem de $f$ que pode ser expresso como: 


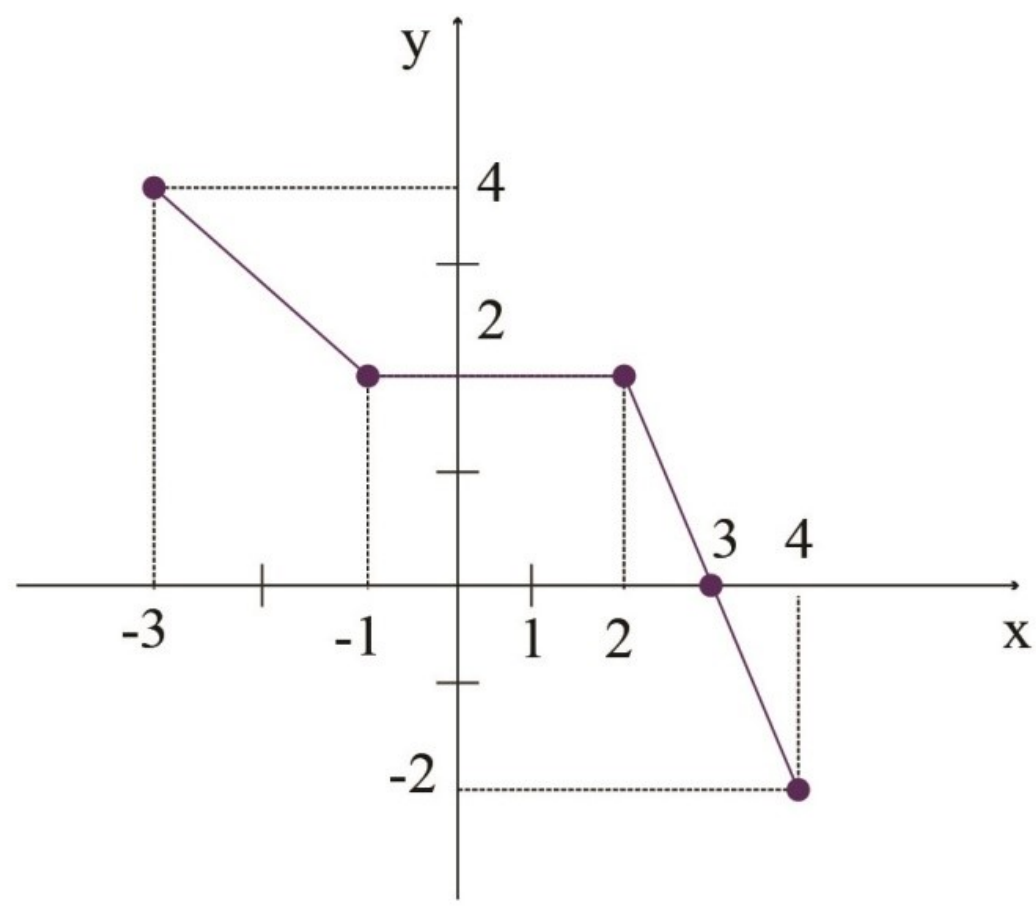

Figura 1.3: Gráfico de uma função $f$ para determinar o domínio e a imagem.

$\operatorname{Im}(f)=y \in \mathbb{R}:-2 \leqslant y \leqslant 4$.

\subsubsection{Crescimento e decrescimento}

Na educação básica (Ensino Fundamental e Ensino Médio), é costumeiro classificar funções do primeiro grau como crescentes ou decrescentes, em função do sinal do que é chamado de coeficiente angular. Porém, crescimento e decrescimento não são conceitos restritos a funções elementares como as polinomiais de primeiro ou segundo graus. Observe suas definições gerais:

Definição 1.7 Seja $f: D \subset \mathbb{R} \rightarrow \mathbb{R}$ uma função.

(i) Dizemos que $f$ é crescente se $x_{1}, x_{2} \in D, x_{1}<x_{2} \rightarrow f\left(x_{1}\right)<f\left(x_{2}\right)$;

(ii) Dizemos que $f$ é não decrescente se $\left.x_{1}, x_{2} \in D, x_{1}<x_{2}\right) f\left(x_{1}\right) \leq f\left(x_{2}\right)$;

(iii) Dizemos que $f$ é decrescente se $x_{1}, x_{2} \in D, x_{1}<x_{2} \rightarrow f\left(x_{1}\right)>f\left(x_{2}\right)$;

(iv) Dizemos que $f$ é não crescente se $x_{1}, x_{2} \in D, x_{1}<x_{2} \rightarrow f\left(x_{1}\right) \leq f\left(x_{2}\right)$ : Diz-se que $f$ é monótona se $f$ se encaixa em uma das quatro definições acima.

Vejamos alguns exemplos:

Exemplo 1.8 Seja uma função $f: \mathbb{R} \rightarrow \mathbb{R}$ definida por $f(x)=3 x-2$. Observe: 
$x_{1}<x_{2} \rightarrow 3 x_{1}<3 x_{2} \rightarrow 3 x_{1}-2<3 x_{2}-2 \rightarrow f\left(x_{1}\right)<f\left(x_{2}\right) ;$

o que de acordo com o item (i) da definição anterior classifica $f$ como crescente.

Exemplo 1.9 Seja uma função $g: \mathbb{R} \rightarrow \mathbb{R}$ definida por $g(x)=-4 x+1$. Observe:

$x_{1}<x_{2} \rightarrow(-4) x_{1}>(-4) x_{2} \rightarrow-4 x_{1}+1>-4 x_{2}+1 \rightarrow g\left(x_{1}\right)>g\left(x_{2}\right) ;$

o que de acordo com item (iii) da definição anterior classifica g como decrescente.

É evidente que uma função pode ser crescente em um determinado intervalo do domínio e decrescente em outro. Observe o seguinte exemplo:

Exemplo 1.10 Seja uma função $h: \mathbb{R} \rightarrow \mathbb{R}$, cujo gráfico está representado na figura 1.4: Podemos notar que $h$ é crescente nos intervalos $]-\infty ;-1[$ e $] 1 ; \infty[$, e decrescente no intervalo $]-1 ; 1[$.

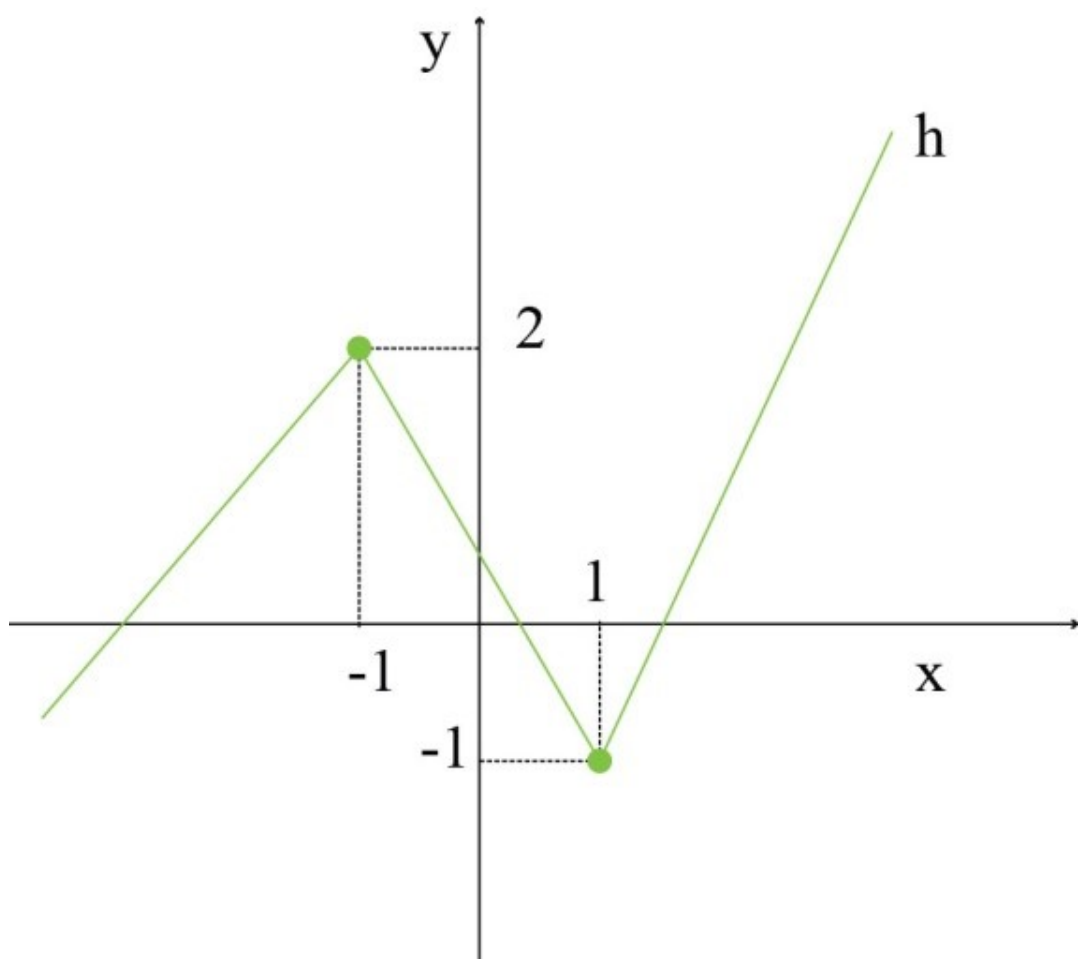

Figura 1.4: Gráfico da função $h: \mathbb{R} \rightarrow \mathbb{R}$, crescente em um determinado intervalo e decrescente em outro.

\subsection{Função composta e função inversa}

Abordaremos nesta seção a composição de funções e também as funções inversas. 


\subsubsection{Função composta}

Definição 1.8 Sejam $f: A \rightarrow B$ e $g: B \rightarrow C$ funções tais que o domínio de $g$ é igual ao contradomínio de $f$. Neste caso, definimos a função composta $g \circ f: A \rightarrow C$, que consiste em aplicar primeiramente a função $f$ e em seguida a função $g$. De maneira mais precisa, $(g \circ f)(x)=g(f(x))$ para todo $x \in A$. Geralmente, basta que a imagem $f(A)$ da função $f$ esteja contida no dominio de $g$ para que a definição $(g \circ f)(x)=$ $g(f(x))$ faça sentido e forneça a função composta $g \circ f: A \rightarrow C$.

Vale também destacar que se $f: A \rightarrow B$ e $g: B \rightarrow C$ são injetivas então $g \circ f$ : $A \rightarrow C$ é injetiva. Assim como a composta de funções sobrejetivas é sobrejetiva e a composta de duas bijeções é uma bijeção. Podemos representar também a composta $g \circ f$ através do diagrama da figura 1.5:

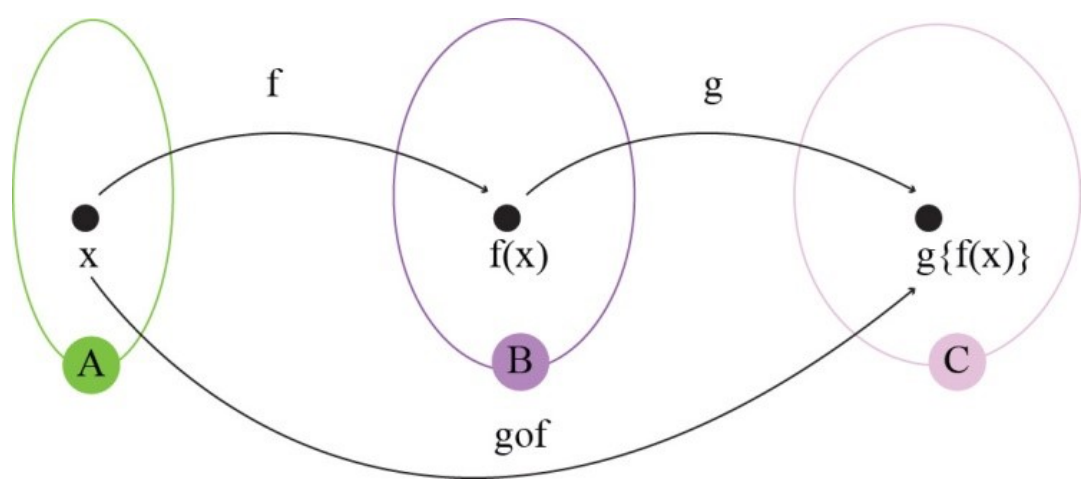

Figura 1.5: Gráfico que ilustra a composição de duas funções.

Vejamos alguns exemplos:

Exemplo 1.11 Sejam os conjuntos $A=\{-1 ; 0 ; 1 ; 2\} ; B=\{0 ; 1 ; 2 ; 3 ; 4\}$ e $C=$ $\{1 ; 3 ; 5 ; 7 ; 9 ; 11 ; 13 ; 15 ; 17\}$ e as funções $f: A \rightarrow B$ definida por $f(x)=2 x^{2}$ e $g: B \rightarrow C$ definida por $g(x)=2 x+1$.

Aplicando $f$ nos elementos de A obtemos:

$$
f(-1)=2 ; f(0)=0 ; f(1)=2 \text { e } f(2)=8 .
$$

Agora, aplicando $g$ nas imagens dos elementos do domínio de $f$, teremos:

$$
g(2)=5 ; g(0)=1 \text { e } g(8)=17
$$

Note que o elemento - 1 de A foi transformado em 5 pela composta $g \circ f$, ou seja,

$$
(g \circ f)(-1)=g(f(-1))=5 .
$$


Do mesmo modo temos:

$$
(g \circ f)(0)=g(f(0))=1,(g \circ f)(1)=g(f(1))=5 \text { e }(g \circ f)(2)=g(f(2))=17 .
$$

Nesse exemplo, vamos considerar os conjuntos $A, B$ e $C$, todos iguais a $\mathbb{R}$ e as mesmas funções $f$ e $g$. Podemos encontrar a expressão da função composta $g \circ f$ da seguinte forma:

$$
(g \circ f)(x)=g(f(x))=2 f(x)+1=2\left(2 x^{2}\right)+1=4 x^{2}+1
$$

Exemplo 1.12 Sejam $f: \mathbb{R} \rightarrow \mathbb{R}$ e $g: \mathbb{R} \rightarrow \mathbb{R}$ definidas por $f(x)=x-1$ e $g(x)=x^{2}+x+1$. Notemos que:

$$
(g \circ f)(x)=g(f(x))=[f(x)]^{2}+f(x)+1=(x-1)^{2}+(x-1)+1=x^{2}-x+1:
$$

Ou seja, a composta $g$ com $f$ será:

$g \circ f: \mathbb{R} \rightarrow \mathbb{R}$ tal que $(g \circ f)(x)=x^{2}-x+1$.

Teorema 1.1 (Associatividade da composição de funções) Quaisquer que sejam as funções $f: A \rightarrow B, g: B \rightarrow C$ e $h: C \rightarrow D$, tem-se:

$$
((h \circ g) \circ f)(x)=(h \circ(g \circ f))(x)
$$

Demonstração: Consideremos um elemento qualquer $x$ de $A$ e coloquemos $f(x)=$ $m, g(m)=n$ e $h(n)=p$; temos:

$$
((h \circ g) \circ f)(x)=(h \circ g)(f(x))=(h \circ g)(m)=h(g(m))=h(n)=p
$$

e notemos que

$(g \circ f)(x)=g(f(x))=g(m)=n$

portanto,

$(h \circ(g \circ f))(x)=h(g \circ f)(x)=h(n)=p$

então temos: $((h \circ g) \circ f)(x)=(h \circ(g \circ f))(x)$; para todo $x$ de $A$. 


\subsection{Função inversa}

Definição 1.9 Se existe uma função $g: Y \rightarrow X$ tal que $f \circ g=I_{Y}$ e $g \circ f=I_{X}$, diz que a função $f: X \rightarrow Y$ é invertível.

Observamos que $I_{A}$ denota a função identidade do conjunto $A$, ou seja, $I_{A}: A \rightarrow A$, $I_{A}(x)=x$. Neste caso, a função $g$ é dita função inversa de $f$ e é denotada por $g=f^{-1}$.

Geralmente, não é fácil aplicar diretamente a definição anterior para verificar que uma função não é invertível, pois deve-se mostrar que não existe nenhuma função que satisfaça as duas condições da definição. Por isso, é importante que se entenda que injetividade e sobrejetividade são condições que garantem a existência da função inversa.

Observe o seguinte teorema.

Teorema 1.2 Uma função $f: I_{X} \rightarrow I_{Y}$ é bijetiva se, e somente se, é invertível.

Demonstração : Por hipótese existe $g: Y \rightarrow X$ tal que:

(i) $f \circ g=I_{Y} \mathrm{e}$

(ii) $g \circ f=I_{X}$.

Toma-se $y \in Y$ qualquer. Seja $x=g(y)$. Da condição (i) acima, segue que $f(x)=f(g(y))=f \circ g(y)=I_{Y}(y)=y$.

Então, $f$ é sobrejetiva.

Tomemos $x_{1} ; x_{2} \in X$ tais que $f\left(x_{1}\right)=f\left(x_{2}\right)$.

Logo, $g \circ f\left(x_{1}\right)=g \circ f\left(x_{2}\right)$.

Da condição (ii), segue que $I_{X}\left(x_{1}\right)=I_{X}\left(x_{2}\right)$, logo, $x_{1}=x_{2}$.

Então, $f$ é injetiva.

Reciprocamente, se $f$ é bijetiva, desejamos construir uma função $g: Y \rightarrow X$ satisfazendo as condições (i) e (ii) da definição de função invertível. Dado $y \in Y$ qualquer, como $f$ é sobrejetiva, existe $x \in X$ tal que $f(x)=y$ e, como $f$ é injetiva, o elemento $x$ com esta propriedade é único. Assim, definimos $g(y)$ como o único $x \in X$ tal que $f(x)=y$.

As duas condições desejadas decorrem imediatamente da construção de g. Neste sentido, consideremos alguns exemplos:

Exemplo 1.13 Sejam $f: \mathbb{R} \rightarrow\left[0 ;+\infty\left[\right.\right.$ e $g:\left[0 ;+\infty\left[\rightarrow \mathbb{R}\right.\right.$ definidas por $f(x)=x^{2} e$ $g(y)=\sqrt{y}$. Tem-se $f(g(y))=y$ para todo $y>0$ mas $g(f(x))$ só é igual a $x$ quando $x>0$. Se $x \in \mathbb{R}$ for negativo então $g(f(x))=-x$.

Portanto, $g$ não é inversa de $f$. Se considerarmos a restrição de $f$ a $[0 ;+\infty[$, isto é, a função $F:\left[0 ;+\infty\left[\rightarrow\left[0 ;+\infty\left[\right.\right.\right.\right.$, dada por $F(x)=x^{2}$, então $F$ é uma correspondência biunívoca, e sua inversa é $G:[0 ;+\infty[\rightarrow[0 ;+\infty[$, dada por $G(y)=\sqrt{y}$, pois $G(F(x))=$ $G\left(x^{2}\right)=\sqrt{x^{2}}=x$ e $F(G(y))=F(\sqrt{y})=(\sqrt{y})^{2}=y$ para quaisquer $x \geq 0$ e $y \geq 0$. 
Observe que nenhuma função $\phi:[0 ;+\infty[\rightarrow \mathbb{R}$ pode ser inversa de $f: \mathbb{R} \rightarrow[0 ;+\infty[$ porque $f$ não é injetiva.

Exemplo 1.14 Generalizando, para todo $n \in \mathbb{N}$, a função $x \rightarrow x^{n}$ é uma correspondência biunívoca de $[0 ;+\infty$ [ sobre si mesmo, cuja inversa é $y \mapsto \sqrt[n]{y}$. Se $n$ é par, então $x \mapsto x^{n}$ é uma correspondência biunívoca de $[0 ;+\infty[$ sobre si mesmo, cuja inversa é $y \mapsto \sqrt[n]{y}$.

Se $n$ é impar, então $x \mapsto x^{n}$ é uma correspondência biunívoca de $\mathbb{R}$ sobre si mesmo, cuja inversa $k: \mathbb{R} \rightarrow \mathbb{R}$ é dada por $k(y) \mapsto \sqrt[n]{y}$. 


\section{Capítulo 2}

\section{O Estudo dos Pontos de Máximo e Mínimo de uma Função Quadrática no Ensino Médio}

De acordo com o Currículo da Educação Básica do Distrito Federal, os conteúdos trabalhados na dimensão da lógica, da análise e da representação partem da convicção de que o raciocínio lógico é capaz de romper com os processos de simples memorização de fórmulas e tabelas, pois desenvolve a capacidade de construir conceitos a partir de observações e de experiências vivenciadas dentro e fora da escola.

A ideia de "algebrizar" está relacionada à capacidade de simbolizar, de operar simbolicamente e de interpretar relações simbólicas. É o grande início da modelagem matemática. A lógica algébrica permite ao indivíduo traduzir uma situação-problema em linguagem matemática a partir da qual são aplicadas rotinas de cálculos e algoritmos.

Esse raciocínio contribui para a análise dos fatos, promove o pensamento científico e desenvolve ações de manipulação de objetos de aprendizagem, de operacionalização, de representação e de abstração. Nesse contexto, a representação assume, na Matemática, o papel de construir modelos simbólicos de diversos fenômenos, contribuindo para a percepção do conhecimento no âmbito dos multiletramentos. Dessa forma, a lógica, a análise e a representação devem atuar em conjunto, colaborando para que os estudantes possam ter uma visão crítica e coerente ao interpretar e agir sobre os fatos.

$\mathrm{Na}$ educação básica, o aluno deve desenvolver habilidades e competências que o ajudem a desenvolver seu pensamento lógico-matemático. Desenvolver o pensamento funcional e raciocinar quantitativamente significa pensar em termos de relações e suas várias representações sejam elas algébricas, geométricas, tabulares ou gráficas e também, modelar e resolver problemas através da aplicação de soluções analíticas. O aluno deve descrever com exatidão as características de uma função quadrática, tais como seu crescimento, decrescimento, valores máximos e mínimos de modo que 
contribua para a resolução de questões envolvendo equações do $2^{\circ}$ grau.

Mas, no Ensino Médio, os problemas cujo objetivo seja encontrar máximos e mínimos não devem se restringir a calcular valores utilizando fórmulas prontas, sem justificativa ou demonstração para tal. Esse hábito reforça o conceito de que Matemática se resume à memorização de fórmulas. Os PCNs [7] vão de encontro a esse conceito, já que dizem que a atividade matemática deve ter como ponto de partida a resolução de problemas. Assim, o aluno valoriza a disciplina de modo a estimular sua compreensão das coisas ao seu redor e perceba a matemática como um estímulo para o interesse e desenvolva a capacidade de resolução de problemas, compartilhando ideias, criando estratégias, desenvolvendo questionamentos e aplicando os conceitos construídos.

Trataremos nesta seção somente os pontos de mínimos e máximos das funções quadráticas, enfocando naquilo que se pensa como sendo a abordagem mais adequada sobre o tema para discentes do Ensino Médio. Como pode ser visto nos livros didáticos do Ensino Médio, chama-se de Função Quadrática, uma função do tipo $f: \mathbb{R} \rightarrow \mathbb{R}$ se existem $a, b$ e $c$ todos reais e a não-nulo, tal que, para todo $x \in \mathbb{R}, f(x)=a x^{2}+b x+c$. O gráfico desse tipo de função é a cônica conhecida como parábola, cuja direção da sua concavidade depende do valor do coeficiente a: para cima, quando $a>0$ ou para baixo, quando $a<0$.

Forma canônica da Função Quadrática é como essa última forma pode ser denominada. Observando-a, podemos notar que apenas $x$ é variável e, por consequência, que $a, \frac{b}{2 a}, \frac{\Delta}{4 a^{2}}$ são constantes. Observamos também que se $a>0$, o valor mínimo de $f(x)$ ocorre quando ocorrer o valor mínimo para $\left(x+\frac{b}{2 a}\right)^{2}-\frac{\Delta}{4 a^{2}}$; como $\left(x+\frac{b}{2 a}\right)^{2}$ é sempre maior ou igual a zero, seu valor mínimo ocorre quando $x+\frac{b}{2 a}=0$, ou seja, quando $x=\frac{-b}{2 a}$; nessa situação, o valor mínimo de $f(x)$ é $f(x)=a\left[0-\frac{\Delta}{4 a^{2}}\right]=\frac{-\Delta}{4 a}$.

Por meio de raciocínio semelhante, se $a<0$, pode-se concluir que o valor máximo de $f(x)$ ocorre quando $x=\frac{-b}{2 a}$, o que leva ao valor máximo de $f(x)=\frac{-\Delta}{4 a}$.

Nesse caso, os valores de $x$ e de $f(x)$ são conhecidos, respectivamente, por $x_{v}$ ( " $x$ " do vértice da parábola) e $y_{v}$ (" $y$ " do vértice da parábola). Os alunos devem, portanto, ao concluírem o Ensino Médio, resolver os problemas que envolvam cálculos dos valores máximos e mínimos de funções quadráticas por meio da utilização das "fórmulas" deduzidas acima para $x_{v}$ e $y_{v}$.

Formular e equacionar problemas é uma estratégia básica e extremamente eficiente. Os problemas que envolvem, em diferentes contextos, questões de otimização, sejam problemas de máximo ou de mínimo podem ser mais um atrativo na constante busca da contextualização de conteúdos estudados. 


\section{Capítulo 3}

\section{Derivadas}

\subsection{História das Derivadas}

Além daquelas encontradas nos livros de cálculo, a derivada tem inúmeras aplicações em diversas áreas do conhecimento. Esboçar gráficos de polinômios é um dos exemplos da utilização desse recurso. Curiosamente a derivada estava presente em problemas geométricos de tangência, por exemplo, como determinar uma reta que intersecta uma dada curva em um único ponto.

No século XVII, Pierre Fermat [6] (1601 - 1665) denominou a família de parábolas superiores utilizando a fórmula $y=t^{n}$, onde $t$ é constante e $n=2,3,4,5, \cdots$. Ao introduzir símbolos algébricos visando estudar a geometria de curvas, forneceu rica colaboração para o desenvolvimento da derivada e do cálculo diferencial e integral de modo geral. Fermat foi quem desenvolveu um procedimento algébrico para determinar os máximos e mínimos sobre uma determinada curva. Em uma linguagem geométrica, esses pontos pertencem à reta tangente à curva e suas respectivas inclinações são iguais a zero. Christiaan Huygens [6] (1629 - 1695) criou um processo algébrico que gerou os pontos de inflexão de uma curva e este fato está relacionado à segunda derivada da função. Isaac Newton [6] (1642 - 1727) e Gottfried Wilhelm Leibniz [6] (1646 - 1716), apesar de realizarem trabalhos independentes entre si, mostraram a relação entre as derivadas e as integrais. Por exemplo, em suas contribuições para o Teorema Fundamental do Cálculo, ambos tinham seguidores que colaboraram para o desenvolvimento do cálculo no decorrer do tempo. Outros matemáticos importantes também colaboraram para o desenvolvimento do mesmo, por exemplo, Jean le Rond d Alembert [6] (1717 - 1783). Contudo, somente no século XIX a definição atual de derivada foi dada por Augustin Louis Cauchy [6] (1789 - 1857). Segundo ele, a derivada é o limite de $\frac{f(x+h)-f(x)}{h}$, quando $h$ se aproxima de 0. Dessa maneira, o formato da função que serve como o limite da razão mencionada, dependerá do formato da função $y=f(x)$ dada. A fim de mostrar esta dependência, esta nova função é denominada Derivada. Nas 
seguintes seções, podemos ver como o cálculo está relacionado no currículo do ensino médio e sua importância para este nível da educação básica.

\subsection{Conceitos Básicos: Limites e Derivadas}

\subsubsection{Noções de Limites}

No estudo de progressões geométricas no ensino médio, há o primeiro contato com a noção de limite. Este fato podia ser percebido quando mencionado o exemplo do comportamento da sequência $\frac{1}{2}, \frac{1}{4}, \frac{1}{8}, \cdots, \frac{1}{2^{n}}, n \in \mathbb{N}$, quando $n$ tende ao infinito. Não é difícil enxergar que, à medida que o valor de $n$ cresce, $\frac{1}{2^{n}}$ se aproxima mais de zero. Logo, essa sequência é convergente, ou seja, seu limite se anula quando $n$ tende ao infinito. Denotamos por:

$$
\lim _{x \rightarrow \infty} \frac{1}{2^{x}}=0
$$

Além disso, pode-se usar as funções na compreensão do conceito de limite. Por exemplo, analisando o que ocorre com os valores de $f(x)=\frac{4 x^{2}-8 x}{x-2}$, de domínio $\mathbb{R}-\{2\}$, quando $x$ se aproxima de 2 , pode-se perceber que como $x \neq 2$, dividindo-se o numerador e o denominador por $x-2$, obtém-se $f(x)=\frac{4 x(x-2)}{x-2}=4 x$. Observe o gráfico:

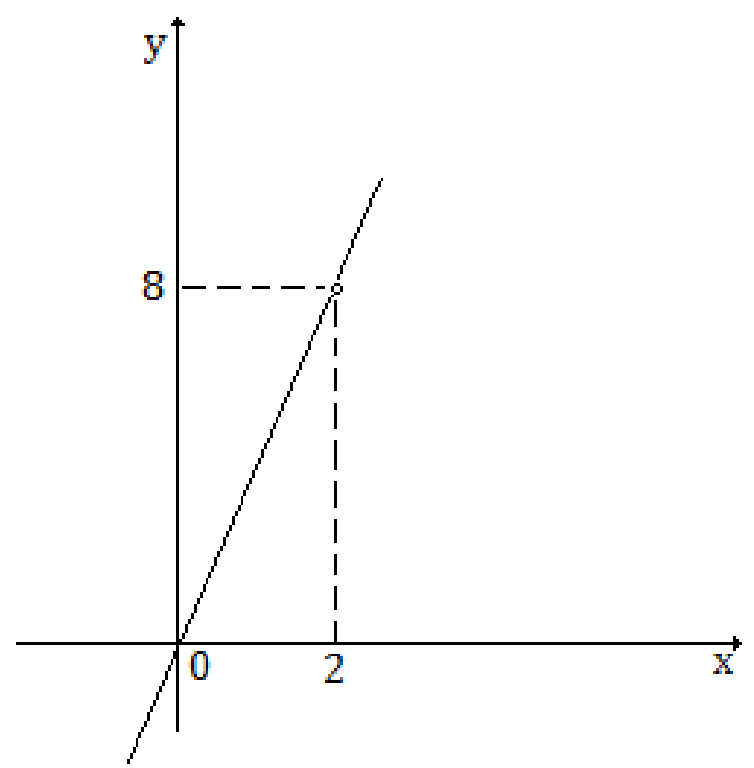

Figura 3.1: Gráfico de $f(x)=\frac{4 x^{2}-8 x}{x-2}$

Agora, atribuindo valores próximos de 2 para $x$, tanto maiores quanto menores e verificando o que ocorre com a imagem dos mesmos. 
Observe:

$f(1,99)=7,96$

$f(1,999)=7,996$

$f(1,9999)=7,9996$

$f(1,99999)=7,99996$

$\mathrm{e}$

$f(2,01)=8,04$

$f(2,001)=8,004$

$f(2,0001)=8,0004$

$f(2,00001)=8,00004$

Após os cálculos e analisando o gráfico a seguir percebemos que, para valores de $x$ cada vez mais próximos de $2, f(x)$ assume valores cada vez mais próximos de 8 . Logo, o limite de $f(x)$, quando $x$ tende a 2 , é 8 .

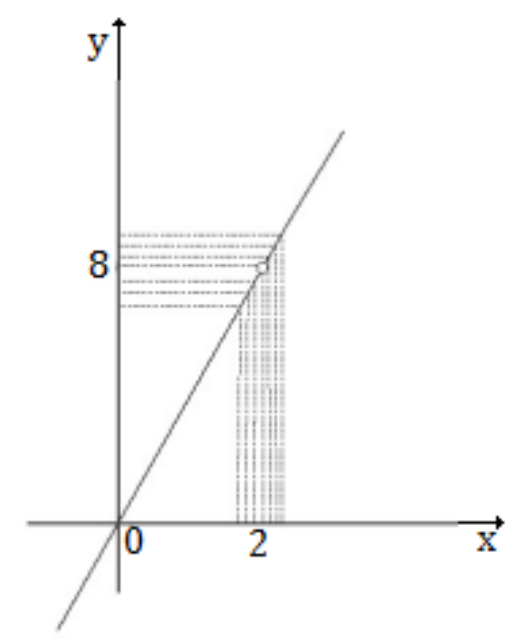

Figura 3.2: Gráfico de $f(x)=4 x, \operatorname{com} x$ tendendo a 2

Em símbolos temos:

$$
\lim _{x \rightarrow 2} f(x)=8
$$

Utilizando outras palavras, dizemos que $f(x)$ se aproxima de $b$ quando $x$ se aproxima de $a$, se toda possível sequência de valores de $x$, estes pertencentes ao domínio da função, tendendo para a (mas diferentes de $a$ ), corresponde a uma sequência de valores de $f(x)$ tendendo para $b$. Observe o gráfico 3.3: 


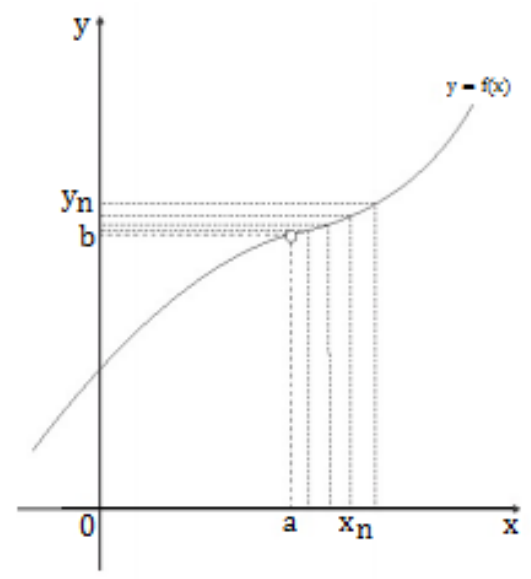

Figura 3.3: Gráfico de sequências tendendo a $a$.

Generalizando:

Definição 3.1 Seja $f$ uma função que é definida para todo número real em algum intervalo aberto que contenha a, exceto possivelmente o próprio número a. O limite de $f(x)$, quando $x$ tende a a, será b, escrito como $\lim _{x \rightarrow a} f(x)=b$, se a seguinte afirmativa for verdadeira: Dado $\varepsilon>0$ qualquer, existe um $\delta>0$, tal que se $0<|x-a|<\delta$ então $|f(x)-b|<\varepsilon$.

Observação 3.1 No cálculo do $\lim f(x)$, o foco deve ser no comportamento de $f(x)$ quando $x$ se aproxima de a e não no que ocorre com $f(x)$ para $x=a$. No exemplo discutido, vimos que existe $\lim _{x \rightarrow 2} f(x)$, mas não existe $f(2)$.

\subsubsection{O Problema da Reta Tangente}

Dada uma função $f$, considere $y=f(x), x_{0}$ um ponto do domínio de $f$ e $x_{1}=x_{0}+h$, onde $x_{1}$ pertence ao domínio da função $f$. Considere também os pontos distintos $A=\left(x_{0}, f\left(x_{0}\right)\right)$ e $B=\left(x_{1}, f\left(x_{1}\right)\right)$ pertencente ao gráfico da função e a reta $r$ secante que passa por eles. Considerando o caso em que $h>0$, o coeficiente angular da reta $r$ é:

$$
\frac{f\left(x_{1}\right)-f\left(x_{0}\right)}{x_{1}-x_{0}}=\frac{f\left(x_{0}+h\right)-f\left(x_{0}\right)}{h} .
$$


Observe o gráfico:

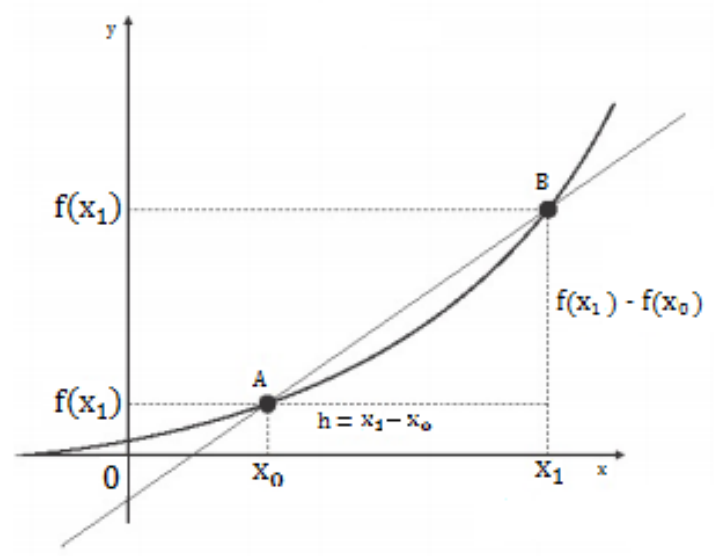

Figura 3.4: Reta secante a uma curva

Quando $x_{1}$ tende a $x_{0}$, o coeficiente angular da reta $r$ tende $a$

$$
\lim _{x \rightarrow x_{0}} \frac{f(x)-f\left(x_{0}\right)}{x-x_{0}}
$$

Quando $h$ se aproxima de zero (ou seja, quando $x_{1}$ se aproxima de $x_{0}$ ), obtemos várias retas secantes que cortam a curva em dois pontos $A$ e $B_{i}$, cada vez mais próximos. Veja a figura 3.5:

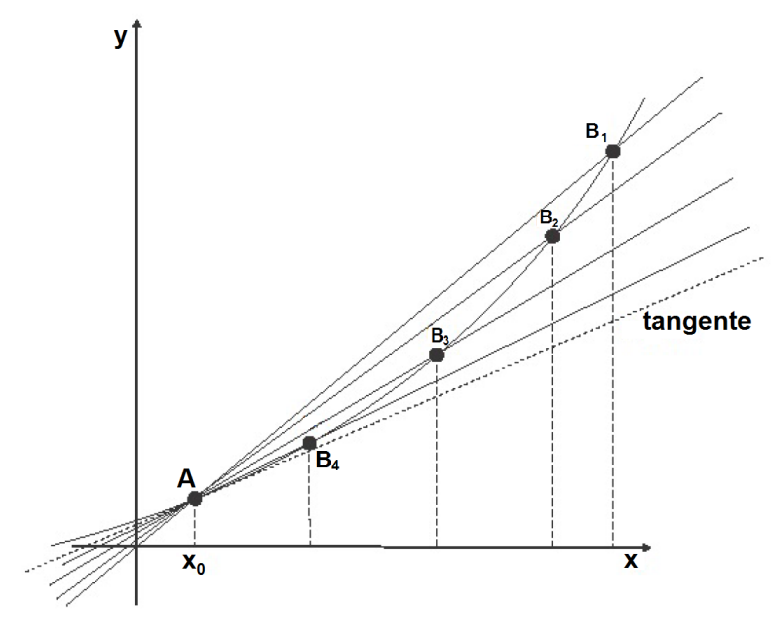

Figura 3.5: Gráfico com algumas retas secantes e uma tangente

Intuitivamente, quando $x_{0}+h$ se aproxima de $x_{0}$ então os pontos $f\left(x_{0}+h\right)$ e $f\left(x_{0}\right)$, nos quais a secante corta a curva, ficam cada vez mais próximos. Desse modo estas secantes se aproximam cada vez mais da tangente em $x_{0}$. Quando $h$ tende a 0 , e o quociente $\frac{f\left(x_{0}+h\right)-f\left(x_{0}\right)}{h}$, se aproxima de um determinado valor, esse deverá então ser o coeficiente angular da reta tangente. Assim, definimos a reta tangente como a reta que 
passa por A e cujo coeficiente angular é dado por,

$$
f^{\prime}\left(x_{0}\right)=\lim _{h \rightarrow 0} \frac{f\left(x_{0}+h\right)-f\left(x_{0}\right)}{h} .
$$

Observação 3.2 Não há reta tangente no ponto dado, se o limite acima não existir.

\subsubsection{Definição de Derivada}

Considerando $f$ uma função e $x_{0}$ um ponto de seu domínio, denomina-se derivada de $f$ em $x_{0}$ e indica-se por $f^{\prime}\left(x_{0}\right)$ o limite a seguir, quando existe e é finito.

$$
f^{\prime}\left(x_{0}\right)=\lim _{h \rightarrow 0} \frac{f\left(x_{0}+h\right)-f\left(x_{0}\right)}{h} .
$$

Assim, se existe a derivada em $x_{0}$ de uma função, então esta será derivável em $x_{0}$. A função será derivável em um intervalo aberto, se ela for derivável em todo número nesse intervalo aberto. Nas seções seguintes, detalharemos mais alguns aspectos sobre a derivada já que o principal interesse são as funções polinomiais, a maioria do $2^{\circ}$ grau, já que na educação básica, o enfoque é mais frequente nesse tipo. Para isso precisamos detalhar como são as derivadas das funções constantes, soma e produto de duas funções e de funções do tipo $f(x)=x^{n}$. Além disso, mostrar como usar as derivadas para obter valores máximos e mínimos em diversas situações.

\subsubsection{Regras de Derivação}

Certas funções são formadas a partir de outras funções, por meio de somas, diferenças, produtos. Outras operações entre funções e suas derivadas podem ser encontradas facilmente, desde que se conheçam certas propriedades da derivação. Consequentemente, aplicar a definição de derivadas para poder calcular a derivada de algumas funções nem sempre será imprescindível.

Sejam $f, g$ e $h$ deriváveis:

a) Função Constante

Seja $f(x)=b, b \in \mathbb{R}$, então

$$
f^{\prime}(x)=0
$$

b) Multiplicação por constante

Seja $g(x)=c \cdot f(x), c \in \mathbb{R}$, então:

$$
g^{\prime}(x)=c \cdot f^{\prime}(x)
$$


c) A Regra da Soma e da Diferença

Seja $h(x)=f(x) \pm g(x)$, temos então:

$h^{\prime}(x)=f^{\prime}(x) \pm g^{\prime}(x)$

d) Regra do Produto

Se $f$ e $g$ forem deriváveis e $h(x)=f(x) \cdot g(x)$, então:

$h^{\prime}(x)=f^{\prime}(x) \cdot g(x)+f(x) \cdot g^{\prime}(x)$

e) Regra do Quociente

Se $f$ e $g$ forem deriváveis e $h(x)=\frac{f(x)}{g(x)}$, então:

$h^{\prime}(x)=\frac{f^{\prime}(x) \cdot g(x)-f(x) \cdot g^{\prime}(x)}{g\left(x^{2}\right)}$

\subsubsection{Derivadas de Funções Elementares}

Como o trabalho tem seu enfoque na Educação Básica, nos limitaremos ao estudo de funções elementares como as funções polinomiais, já que os problemas resolvidos nos capítulos específicos se referem a esse tipo de função.

a) Se $f(x)=x$, então $f^{\prime}(x)=1$. Ou seja, a derivada da função identidade é igual a 1 ;

b) Dada a função $f(x)=x^{n}$, em que $n \in \mathbb{N}$ temos que $f^{\prime}(x)=n \cdot x^{n-1}$;

c) Toda função polinomial é derivável. Além disso, dada uma função polinomial $f(x)=a_{0}+a_{1} x+a_{2} x^{2}+\cdots+a_{n} x^{n}, a_{n} \neq 0$

sua derivada é dada por $f^{\prime}(x)=a_{1}+2 a_{2} x+3 a_{3} x^{2}+\cdots+n a_{n} x^{n-1}$

\subsubsection{Intervalos de Crescimento e Decrescimento}

Relacionar a derivada de uma função à sua propriedade de crescimento. A figura a seguir mostra uma parte do gráfico da função $f(x)=-x^{2}+1$. Observe que $f(x)$ é crescente no intervalo $[-1,0]$ e decrescente no intervalo $[0,1]$. No intervalo em que é crescente, a reta tangente a um ponto qualquer é uma reta crescente (portanto a derivada da função é positiva) e no intervalo em que é decrescente, a reta tangente a um ponto qualquer é uma reta decrescente (portanto a derivada da função é negativa). A derivada é nula em $x=0$.

Desse modo, a relação entre crescimento e derivada é a seguinte: a função é crescente nos intervalos de derivada positiva e decrescente nos intervalos de derivada negativa. 


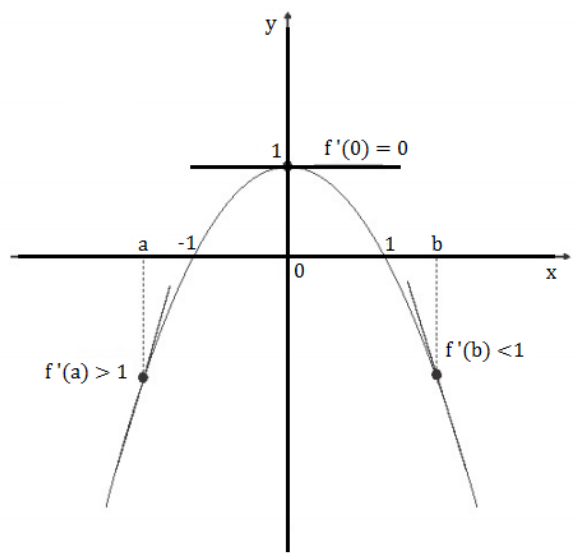

Figura 3.6: Gráfico ilustrando o crescimento e o decrescimento da função $f(x)=-x^{2}+1$

\subsubsection{Máximos e Mínimos}

Definição 3.2 Uma função $f: D \rightarrow \mathbb{R}$ tem máximo absoluto em c se $f(x) \leq f(c)$ para todo $x$ no domínio $D$ de $f$. Neste caso, o valor $f(c)$ é chamado valor máximo de $f$ em $D$.

Definição 3.3 Uma função $f: D \rightarrow \mathbb{R}$ tem mínimo absoluto em c se $f(x) \geq f(c)$ para todo $x$ no dominio $D$ de $f$. Neste caso, o valor $f(c)$ é chamado valor mínimo de $f$ em $D$.

Observação 3.3 Os valores de máximo e mínimo absoluto de uma função são chamados valores extremos da função.

Definição 3.4 Uma função tem máximo local (ou máximo relativo) em um ponto c de seu dominio, se existe intervalo aberto $I$, tal que $c \in I$ e $f(x) \leq f(c)$ para todo $x \in I$. Neste caso, dizemos que $f(c)$ é valor máximo local de $f$.

Definição 3.5 Uma função tem mínimo local (ou mínimo relativo) em um ponto c de seu dominio, se existe intervalo aberto $I$, tal que $c \in I$ e $f(x) \geq f(c)$ para todo $x \in I$. Neste caso, dizemos que $f(c)$ é valor mínimo local de $f$.

Observação 3.4 Os pontos de máximo local e pontos de mínimo local são chamados extremos locais.

Definição 3.6 Um ponto c no domínio de uma função $f$ é chamado ponto crítico se ocorre um dos dois seguintes casos:

- $f$ não é derivável em $x=c$;

- $f$ é derivável em c e $f^{\prime}(c)=0$.

Assim, podemos escrever que: Se $x=c$ é máximo ou mínimo local de $f$ então c é ponto crítico de $f$. 


\subsubsection{Teste da primeira derivada}

Proposição 3.1 Considerando a função $f:[a, b] \rightarrow \mathbb{R}$ contínua e derivável em $(a, b)$ e, também, c um ponto crítico de $f$.

a) Se $f^{\prime}$ passa de positiva para negativa em c, então $f$ tem máximo local em c;

b) Se $f^{\prime}$ passa de negativa para positiva em c, então $f$ tem mínimo local em c;

c) Se $f^{\prime}$ não muda de sinal em c, então não tem máximo nem mínimo local em c.

\section{Demonstração:}

a) Se $f^{\prime}$ passa de positiva para negativa em $c$ então existem $x_{0}, x_{1} \in(a, b), x_{0}<$ $c<x_{1}$, tais que $f^{\prime}(x)>0$ se $x \in\left(x_{0}, c\right)$ e $f^{\prime}(x)<0$ se $x \in\left(c, x_{1}\right)$. Como $f$ é crescente em $\left[x_{0}, c\right]$ e decrescente em $\left[c, x_{1}\right]$, segue que $f(c)$ é valor máximo de $f$ no intervalo $\left[x_{0}, x_{1}\right]$ que contém $c$.

b) Da mesma forma, se $f^{\prime}$ passa de negativa para positiva em $c$, então existe intervalo $\left[x_{0}, x_{1}\right]$ contendo $c$ tal que $f$ é decrescente em $\left[x_{0}, c\right]$ e crescente em $\left[c, x_{1}\right]$. Portanto, $f(c)$ é valor mínimo no intervalo $\left[x_{0}, x_{1}\right]$.

c) Seja $I \subset[a, b]$ um intervalo contendo $c$. Como $f^{\prime}$ não muda de sinal em $c$ então há um intervalo $\left[x_{0}, x_{1}\right]$ contendo $c$ tal que $f$ é crescente (respectivamente, decrescente) em $\left[x_{0}, c\right]$ e contínua crescente (respectivamente, decrescente) em $\left[c, x_{1}\right]$. Aproximando $x_{0}$ e $x_{1}$ de $c$ o que for necessário, podemos supor que $\left[x_{0}, x_{1}\right] \subset I$. Portanto, $f(c)$ não pode ser valor máximo e nem mínimo em $I$.

\subsubsection{Teste da segunda derivada}

Se existe a derivada de $f^{\prime}$, então ela será chamada de segunda derivada ou de função segunda derivada e será denotada por $f^{\prime \prime}$.

Proposição 3.2 Considerando $f$ uma função derivável em um intervalo aberto $I$ e seja $c \in I$ tal que $f^{\prime}(c)=0$. Se existe $f^{\prime \prime}(c)$, então:

a) Se $f^{\prime \prime}(c)<0$, então $f$ possui um máximo local em c;

b) Se $f^{\prime \prime}(c)>0$, então $f$ possui um mínimo local em $c$.

O teste é inconclusivo caso $f^{\prime \prime}(c)=0$.

Demonstração: Suponha que $f^{\prime}(c)=0$ e $f^{\prime \prime}(c)<0$, então

$f^{\prime \prime}\left(x_{0}\right)=\lim _{h \rightarrow c} \frac{f^{\prime}(x)-f^{\prime}(c)}{x-c}$

$=\lim _{h \rightarrow c} \frac{f^{\prime}(c)}{x-c}<0$. 
Logo, há um intervalo $(a, b)$ contendo $c$ tal que $\frac{f^{\prime}(c)}{x-c}<0$ para todo $x \in(a, b)$. Portanto, $a<x<c$ implica que $x-c<0$ e $\frac{f^{\prime}(c)}{x-c}<0$ implica que $f^{\prime}(x)>0 ; c<x<b$ implica que $x-c>0$ e $\frac{f^{\prime}(x)}{x-c}<0$ implica que $f^{\prime}(x)<0$. Portanto, $f$ passa de crescente para decrescente em $c$. Pelo teste da primeira derivada, $f$ tem máximo local em $x=c$. O caso b) é análogo.

Exemplo 3.1 Vamos determinar os pontos de máximo e mínimos relativos da função $f(x)=\frac{1}{2} x^{4}+\frac{1}{3} x^{3}-4 x^{2}-4 x+5$.

Calculando a derivada de $f$, temos:

$f^{\prime}(x)=\frac{1}{2} \cdot 4 x^{3}+\frac{1}{3} \cdot 3 x^{2}-4 \cdot 2 x-4=2 x^{3}+x^{2}-8 x-4$.

Determinemos os pontos críticos igualando $f^{\prime}(x)$ a 0 . Então:

$2 x^{3}+x^{2}-8 x-4=0 \rightarrow(x+2)\left(2 x^{2}-3 x-2\right)=0$.

Assim, obtemos os seguintes pontos críticos: $x=-2, x=\frac{-1}{2}$ e $x=2$. Calculando a segunda derivada obtemos:

$f^{\prime \prime}(x)=2 \cdot 3 x^{2}+2 x-8=6 x^{2}+2 x-8$.

Fazendo o Teste da Segunda Derivada:

$f^{\prime \prime}(-2)=6 \cdot(-2)^{2}+2 \cdot(-2)-8=24-4-8=12>0$.

Logo, $x=-2$ é ponto de mínimo.

$f^{\prime \prime}\left(\frac{-1}{2}\right)=6 \cdot\left(\frac{-1}{2}\right)^{2}+2 \cdot\left(\frac{-1}{2}\right)-8=\frac{6}{4}-1-8=\frac{-15}{2}<0$.

Logo, $x=\frac{-1}{2}$ é ponto de máximo.

$f^{\prime \prime}(2)=6 \cdot 2^{2}+2 \cdot 2-8=24+4-8=20>0$. Logo, $x=2$ é ponto de mínimo. 


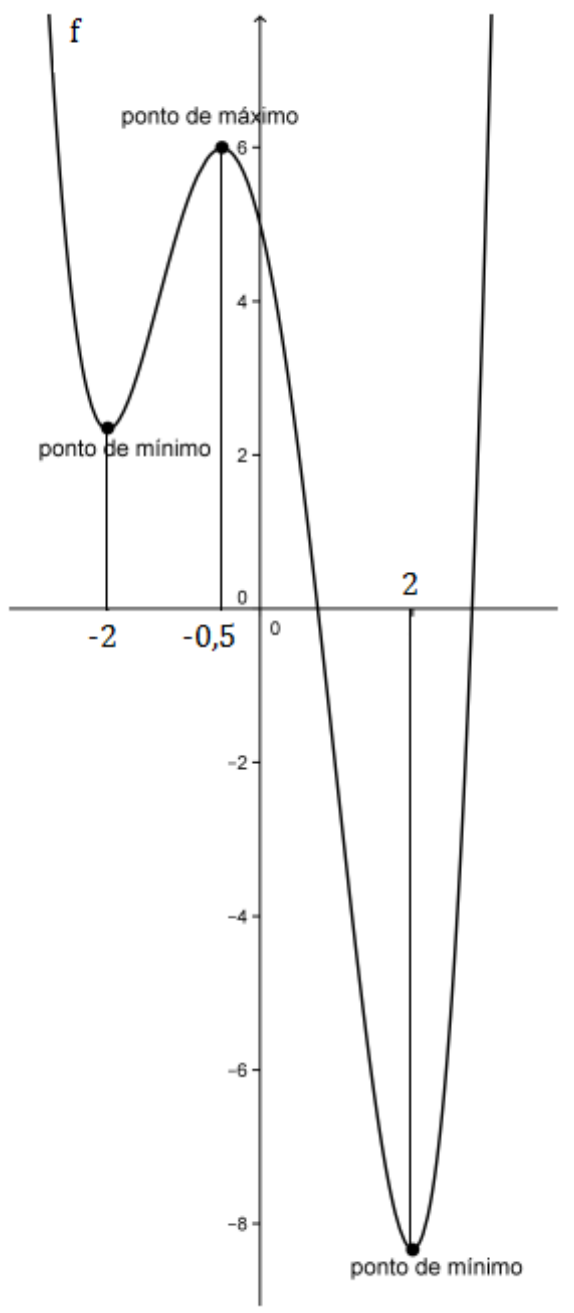

Figura 3.7: exemplo de 3.1 


\section{Capítulo 4}

\section{Máximos e Mínimos de Funções Contínuas}

Na Matemática existe uma variedade de problemas que consiste em encontrar pontos de um conjunto A nos quais a função real $f: A \rightarrow \mathbb{R}$ assume seu valor máximo ou seu valor mínimo. É de suma importância saber da existência desses pontos, antes de qualquer esforço no sentido de resolver problemas dessa natureza. Porém, não podemos deixar de considerar as possibilidades, pois a função pode ser ilimitada superiormente e não possuir valor máximo ou ao contrário, pode ser ilimitada inferiormente, o que implica em não possuir valor mínimo. Contudo, será que o fato de se considerar uma função limitada (superior ou inferiormente) garante a existência de valor máximo ou mínimo ? A resposta é negativa pois, mesmo limitada, a função pode não assumir valor máximo, mínimo ou também, nenhum dos dois em A.

Ao desenvolver esse capítulo apresentaremos conceitos que permitirem assegurar a existência de valores máximos e/ou mínimos de funções contínuas de uma variável reais quando possuem domínio compacto. Este resultado é conhecido como Teorema de Weierstrass e sua demonstração será feita posteriormente, para uma variável real.

\subsection{Existência de Valores Máximos e Mínimos de Funções Contínuas de Uma Variável Real}

O objetivo primordial desta seção é apresentar importantes resultados que levam à construção da demonstração do Teorema de Weierstrass para funções contínuas de uma variável real. Para tanto, trabalharemos inicialmente com alguns teoremas e definições e assim, tal demonstração será feita ao final.

Definição 4.1 Uma sequência de números reais é uma função $x: \mathbb{N} \rightarrow \mathbb{R}$ que associa a cada número natural $n$ um número real $x_{n}$, chamado n-ésimo termo da sequência. 
As notações para uma sequência são $\left(x_{1}, \ldots, x_{n}, \ldots\right),\left(x_{n}\right), n \in \mathbb{N}$ ou simplesmente $\left(x_{n}\right)$. Uma sequência $\left(x_{n}\right)$ diz-se limitada superiormente (ou inferiormente) quando existe $c \in \mathbb{R}$ tal que $x_{n} \leq c$ (respectivamente $x_{n} \geq c$ ), $\forall n \in \mathbb{N}$. Diz-se que a sequência $\left(x_{n}\right)$ é limitada quando ela é limitada superior e inferiormente. Isto equivale a dizer que: $\exists k>0:\left|x_{n}\right| \leq k, \forall n \in \mathbb{N}$.

Dada uma sequência $x=\left(x_{n}\right), n \in \mathbb{N}$, uma subsequência de $x$ é a restrição da função x a um subconjunto infinito $\mathbb{N}^{\prime}=n_{1}<n_{2}<\cdots<n_{k}<\cdots$ de $\mathbb{N}$. As notações para uma subsequência são $x^{\prime}=\left(x_{n}\right) n \in \mathbb{N}^{\prime},\left(x_{n 1}, x_{n 2}, \cdots, x_{n k}, \cdots\right)$ ou $\left(x_{n k}\right), k \in \mathbb{N}$. A notação $\left(x_{n k}\right), k \in \mathbb{N}$ mostra como uma subsequência pode ser considerada como uma sequência, isto é, uma função cujo domínio é $\mathbb{N}$.

Definição 4.2 Dada uma sequência $\left(x_{n}\right)$,

(i) diz-se que $\left(x_{n}\right)$ converge ao ponto $a \in \mathbb{R}$ se $\forall \varepsilon>0, \exists n_{0} \in \mathbb{N} ; n>n_{0} \Longrightarrow$ $\left|x_{n}-a\right|<\varepsilon$.

Escreve-se $x_{n} \longrightarrow a$;

(ii) diz-se que o número real a é limite de $\left(x_{n}\right)$ se, para todo número real $\varepsilon>0$, dado arbitrariamente, pode-se obter $n_{0} \in \mathbb{N}$ tal que todos os termos $x_{n}$ com índice $n>n_{0}$ satisfazem a condição $\left|x_{n}-a\right|<\varepsilon$.

Escreve-se então $a=\lim x_{n}$.

Definição 4.3 Diz-se que um ponto a é aderente ao conjunto $A \subset \mathbb{R}$ quando a é limite de alguma sequência de pontos $\left(x_{n}\right) \in A$. Evidentemente, todo ponto a $\in A$ é aderente a A, bastando tomar todos os $x_{n}=a$.

Chama-se fecho de um conjunto $A$ ao conjunto $\bar{A}$ formado por todos os pontos aderentes a $A$. Tem-se $\bar{A} \subset A$. Se $\bar{A} \subset B$, então $A \subset B$.

Definição 4.4 Um conjunto $F$ diz-se fechado quando todo ponto aderente a $F$ pertence a $F$, isto é, $F=\bar{F}$.

Definição 4.5 Dado um conjunto $L \subset \mathbb{R}$, diz-se que:

(i) L é limitado superiormente quando existe algum $b \in \mathbb{R}$ tal que $x \leqslant b, \forall x \in L$. Neste caso, diz-se que b é uma cota superior de L;

(ii) L é limitado inferiormente quando existe algum $a \in \mathbb{R}$ tal que $a \leqslant x, \forall x \in L$. Neste caso, diz-se que a é uma cota inferior de L;

(iii) L é um conjunto limitado quando é limitado superior e inferiormente. Isto significa que $L$ está contido em algum intervalo limitado $[a, b]$ ou, equivalentemente, que existe $l>0$ tal que $x \in L \Longrightarrow|x| \leqslant l$. Caso o conjunto não seja limitado (ou também limitado superior ou inferiormente), diz-se que é um conjunto ilimitado (ou também ilimitado superior ou inferiormente). 
Definição 4.6 Um conjunto $K \subset \mathbb{R}$ chama-se compacto quando é limitado e fechado. Consequentemente, todo conjunto finito é compacto. Um intervalo do tipo $[a, b]$ é um conjunto compacto. Por outro lado, ]a,b[ é limitado, mas não é fechado, e, portanto, também não é compacto.

Agora, munidos da definição 1.1, provaremos o resultado que segue.

Lema 4.1 Sejam $f: K \rightarrow \mathbb{R}$ um função contínua e $\left(x_{n}\right)$ uma sequência em $K$ compacto. Se $x_{n} \rightarrow a$, então $f\left(x_{n}\right) \rightarrow f(a), \forall a \in K$.

Demonstração: Por hipótese, a função é contínua e $x_{n} \rightarrow a$, ou seja, a sequência $\left(x_{n}\right)$ converge para a. Assim,

(i) pela Definição 1.1, $\forall \varepsilon>0, \exists \delta>0 ; x \in K$ e $|x-a|<\delta \Longrightarrow|f(x)-f(a)|<\varepsilon$;

(ii) pelo item (i) da Definição 2.2, $\forall \varepsilon>0, \exists n_{0} \in \mathbb{N} ; n>n_{0} \Longrightarrow\left|x_{n}-a\right|<\varepsilon$.

Dado $\varepsilon>0$, usando a hipótese (i), $\exists \delta>0 ; x \in K$ e $|x-a|<\delta \Longrightarrow|f(x)-f(a)|<\varepsilon$. (2.1) Para o $\delta$ encontrado, usamos a hipótese (ii) com $\delta$ no papel do $\varepsilon$ e obteremos $n_{0} \in \mathbb{N} ; n>n_{0} \Longrightarrow\left|x_{n}-a\right|<\delta$. (2.2)

Logo, aplicando primeiro (3.2) e depois (3.1), temos $n>n_{0} \Longrightarrow\left|x_{n}-a\right|<\delta \Longrightarrow$ $x_{n} \in K$ e $\left|x_{n}-a\right|<\delta \Longrightarrow\left|f\left(x_{n}\right)-f(a)\right|<\varepsilon$.

Portanto, se $x_{n} \longrightarrow a$, tem-se $f\left(x_{n}\right) \longrightarrow f(a), \forall a \in K$.

Antes de enunciarmos outro resultado importante, definamos supremo e ínfimo de números reais.

Definição 4.7 Seja $K \subset \mathbb{R}$ um conjunto limitado superiormente e não vazio. Um número $b \in \mathbb{R}$ chama-se supremo do conjunto $K$ e escreve-se $b=$ supK, quando é a menor das cotas superiores de $K$. Analogamente, se $K \subset \mathbb{R}$ é um conjunto limitado inferiormente e não vazio, um número $a \in \mathbb{R}$ chama-se ínfimo do conjunto $K e$ escrevesse $a=$ inf $K$ quando é a maior das cotas inferiores de $K$.

Podemos aprofundar um pouco mais nestas definições. De fato, $b=\operatorname{supK}$ quando cumpre as duas condições:

(S1) $\forall x \in K$, tem-se $x \leqslant b$;

(S2) Se $c \in \mathbb{R}$ é tal que $x \leqslant c, \forall x \in K$, então $b \leqslant c$. A condição S2 admite a seguinte reformulação:

(S2') Se $c<b$, então $\exists x \in K$ com $c<x$. Assim, S2' evidencia que nenhum número real menor do que $b$ pode ser cota superior de $K$. Às vezes se exprime S2' da seguinte forma: $\forall \varepsilon>0, \exists x \in K$ tal que $b-\varepsilon<x$.

Analogamente, $a=\inf K$ quando cumpre as duas condições: 
(I1) $\forall x \in K$, tem-se $a \leqslant x$;

(I2) Se $c \in \mathbb{R}$ é tal que $c \leqslant x, \forall x \in K$, então $c \leqslant a$.

A condição I2 pode ser reformulada da seguinte forma: (I2') Se $a<c$, então $\exists x \in K$ com $x<c$. Assim, I2' diz que nenhum número real maior do que a pode ser cota inferior de $K$. Equivalentemente: $\forall \varepsilon>0, \exists x \in K$ tal que $x<a+\varepsilon$. A seguir enunciaremos uma propriedade do supremo de um subconjunto dos números reais, a qual é conhecida como Axioma do Supremo.

Axioma 4.1 Todo conjunto de números reais, não vazio e limitado superiormente, admite supremo.

Para prosseguirmos, apresentaremos a definição de sequência monótona, fundamental para demonstrarmos os resultados que veremos em breve.

Definição 4.8 Diz-se que uma sequência $\left(x_{n}\right)$ é monótona quando $x_{n} \leq x_{n+1}, \forall n \in \mathbb{N}$ ou quando, $x_{n+1} \leq x_{n}, \forall n \in \mathbb{N}$.

Complementando, no primeiro caso, diz-se que $\left(x_{n}\right)$ é monótona não decrescente e, no segundo, que $\left(x_{n}\right)$ é monótona não crescente. Se, mais precisamente, tivermos $x_{n}<x_{n+1}$ (respectivamente, $\left.x_{n}>x_{n+1}\right), \forall n \in \mathbb{N}$, dizemos que a sequência é crescente (respectivamente, decrescente). Toda sequência monótona não crescente (respectivamente, não decrescente) é limitada superiormente (respectivamente, inferiormente) pelo seu primeiro termo. A fim de que ela seja limitada é suficiente que possua uma subsequência limitada. Desta forma, seja $\left(x_{n}^{\prime}\right) n^{\prime} \in \mathbb{N}^{\prime}$ uma subsequência limitada da sequência monótona (digamos não decrescente) $\left(x_{n}\right)$. Temos $x_{n}^{\prime} \leqslant c, \forall n \in \mathbb{N}^{\prime}$. Dado qualquer $n \in \mathbb{N}, \exists n^{\prime} \in \mathbb{N}^{\prime}$ tal que $n<n^{\prime}$. Então, $x_{n} \leqslant x_{n}^{\prime} \leqslant c$. O teorema a seguir, nos dá uma condição suficiente para que uma sequência convirja. Através da tentativa de demonstrá-lo ao preparar suas aulas, que o matemático alemão R. Dedekind percebeu a necessidade de uma conceituação precisa de número real, na metade do século XIX.

Teorema 4.1 Toda sequência monótona limitada é convergente.

Demonstração: Tomemos uma sequência $\left(x_{n}\right)$ monótona não decrescente e limitada. Sejam $K=x_{1}, \cdots, x_{n}, \cdots$ e $a=\sup K$. Afirmamos que $a=\lim x_{n}$. Assim, dado $\varepsilon>0$, o número $a-\varepsilon$ não é cota superior de $K$. Logo, pela condição S2' do complemento da definição de supremo e ínfimo de um conjunto, $\exists n_{0} \in \mathbb{N}$ tal que $a-\varepsilon<x_{n_{0}}<a$. Assim, $n_{0}<n \Longrightarrow a-\varepsilon<x_{n_{0}} \leq x_{n} \leq a<a+\varepsilon \Longrightarrow a-\varepsilon<x_{n}<a+\varepsilon \Longrightarrow$ $-\varepsilon<x_{n}<a<\varepsilon \Longrightarrow\left|x_{n}-a\right|<\varepsilon$ e, pelo item (i) da definição 2.2, ( $\left.x_{n}\right)$ converge ao ponto $a$. $\operatorname{Logo}, \lim x_{n}=a$. Analogamente, se tomarmos uma sequência $\left(x_{n}\right)$ monótona não crescente e limitada, então $\lim x_{n}$ é o ínfimo do conjunto dos valores $x_{n}$.

Através do teorema anterior, demonstra-se o corolário seguinte, também conhecido como Teorema de Bolzano-Weierstrass. 
Corolário 4.1 (Teorema de Bolzano-Weierstrass) Toda sequência limitada de números reais possui uma subsequência convergente.

Demonstração: Pelo Teorema 3.1, basta mostrar que toda sequência $\left(x_{n}\right)$ possui uma subsequência monótona. Antes de mais nada, diz-se que um termo $x_{n}$ da sequência dada é destacado quando $x_{n} \geq x_{p}, \forall p>n$. Seja $D \subset \mathbb{N}$ o conjunto dos índices $n$ tais que $x_{n}$ é um termo destacado. Temos duas possibilidades para $D$ : ser um conjunto infinito ou um conjunto finito. Se $\mathrm{D}$ for um conjunto infinito, ou seja, $D=\left\{n_{1}<\right.$ $\left.n_{2}<\cdots<n_{k}<\cdots\right\}$, então a subsequência $\left(x_{n}\right)_{n} \in D$ será monótona não-crescente. Entretanto, se $D$ for finito, tomemos $n_{1} \in \mathbb{N}$ como um índice maior de todos os $n \in D$, então $x_{n 1}$ não é destacado, visto que $\nexists n \in D$ tal que $n>n_{1} \Longrightarrow x_{n 1} \geqslant x_{n}$. Logo, $\exists$ $n_{2}>n_{1}$ com $x_{n 2}>x_{n 1}$. Além disso, $x_{n 2}$ não é destacado, evidenciando que $\exists n_{3}>n_{2}$ com $x_{n 3}>x_{n 2}>x_{n 1}$. Procedendo da mesma forma, obtemos uma subsequência crescente $x_{n 1}<x_{n 2}<\cdots<x_{n k}<\cdots$.

Portanto, sempre conseguimos uma subsequência monótona.

A seguir apresentaremos dois lemas e suas respectivas demonstrações serão desenvolvidas com base nos resultados vistos até aqui. Estes lemas, após demonstrados, formarão um único resultado, o qual será apresentado como teorema.

Lema 4.2 Seja $f: K \rightarrow \mathbb{R}$, uma função definida no conjunto $K \subset \mathbb{R}$. Se $K$ é um conjunto compacto e $f$ é contínua, então $f(K)$ é um conjunto limitado. Isto é, $x_{1}$ é ponto de mínimo de $f$ e $x_{2}$ é ponto de máximo de $f$.

Demonstração: Suponhamos que $f(K)$ seja um conjunto ilimitado. Assim, $\forall n \in \mathbb{N}$, $\exists y_{n} \in f(K) ;\left|y_{n}\right|>n$. Como $y_{n} \in f(K)$, então $\forall \mathrm{n}, \exists x_{n} \in K ; f\left(x_{n}\right)=y_{n}$. Assim, $\left(x_{n}\right)$ é uma sequência em $K$, com $K$ compacto. Daí, $\left(x_{n}\right)$ é limitada. Pelo Teorema de Bolzano-Weierstrass, existe uma subsequência $\left(x_{n j}\right)$ convergente a algum ponto a, ou seja, $x_{n j} \rightarrow a$. Como $K$ também é fechado, temos que $a \in K$. Disto segue que $f\left(x_{n j}\right) \rightarrow f(a) \Longrightarrow y_{n j} \rightarrow f(a)$, o que contradiz (3.3), pelo fato de $y_{n j}$ não convergir para nenhum ponto. Portanto, se $K$ é compacto e $f$ é contínua, então $f(K)$ é limitado.

Lema 4.3 Seja $f: K \rightarrow \mathbb{R}$, uma função definida no conjunto $K \subset \mathbb{R}$. Se $K$ é um conjunto compacto e $f$ é contínua, então $f(K)$ é um conjunto fechado.

Demonstração: Seja $a \in f(K)$. Assim, $\exists y_{n} \in f(K) ; y_{n} \rightarrow a$.

Assim, $\forall n, \exists x_{n} \in K$ tal que $f\left(x_{n}\right)=y_{n}$. Como $x_{n} \in K$, temos que $\left(x_{n}\right)$ é limitada. Pelo Teorema de Bolzano-Weierstrass, existe uma subsequência $\left(x_{n j}\right)$ tal que $x_{n j} \rightarrow b$. Pelo fato de $K$ ser fechado e $x_{n j} \rightarrow b$, tem-se que $b \in K$. Sabemos que $f$ é contínua, $\operatorname{assim} f\left(x_{n j}\right) \rightarrow f(b)$. Logo, $y_{n j} \rightarrow f(b)$ e, por (3.4), $y_{n j} \rightarrow a$. Da Unicidade do Limite, resulta que $f(b)=a$ e, consequentemente, $a \in f(K)$.

Portanto, $f(K)=f(K)$, ou seja, $f(K)$ é fechado. 
A seguir, enunciaremos mais um teorema, o qual comentaremos brevemente sua demonstração visto que é uma aplicação direta dos resultados obtidos nos lemas anteriores.

Teorema 4.2 Seja $f: K \rightarrow \mathbb{R}$, uma função definida no conjunto $K \subset \mathbb{R}$. Se $f$ é contínua e $K$ é compacto, então $f(K)$ é compacto.

Demonstração: Pelos Lemas 3.2 e 3.3 temos que $f(K)$ é limitado e fechado. Assim, pela definição 3.6, $f(K)$ é compacto. Para finalizarmos esta seção apresentaremos o Teorema de Weierstrass, resultado que garante a existência de valores máximos e mínimos de funções contínuas de uma variável real, cuja demonstração é feita utilizando basicamente os lemas anteriores.

Teorema 4.3 (Teorema de Weierstrass) Seja $f: K \rightarrow \mathbb{R}$, uma função definida no conjunto $K \subset \mathbb{R}$. Se $f$ é contínua e $K$ é compacto, então $\exists x_{1}, x_{2} \in K$ tal que $f\left(x_{1}\right) \leq f(x) \leq f\left(x_{2}\right), \forall x \in K$. Isto é, $x_{1}$ é ponto de mínimo de $f$ e $x_{2}$ é ponto de máximo de $f$.

Demonstração: Por hipótese, $f$ é contínua e $K$ é compacto. Assim, pelo Lema 3.2, $f(K)$ é limitado. Disto, temos que: $\exists a=\inf f(K) \leq f(x) \leq \sup f(K)=b, \forall x \in K$. Pelo Lema 3.3, $f(K)$ também é fechado, ou seja, $a \in f(K)$ e $b \in f(K)$. Portanto, $\exists$ $x_{1}, x_{2} \in K ; a=f\left(x_{1}\right)$ e $b=f\left(x_{2}\right) \Longrightarrow f\left(x_{1}\right) \leq f(x) \leq f\left(x_{2}\right), \forall x \in K$. 


\section{Capítulo 5}

\section{Funções Quadráticas}

Definição 5.1 Uma função $f: \mathbb{R} \rightarrow \mathbb{R}$ é chamada Função Quadrática quando existem $a, b, c \in \mathbb{R}$, com $a \neq 0$, tais que $f(x)=x^{2}+b x+$ c para todo $x \in \mathbb{R}$.

A função quadrática pode vir escrita na sua forma canônica, mostrada a seguir.

$$
\begin{aligned}
& f(x)=a x^{2}+b x+c \\
& =a\left(x^{2}+\frac{b x}{a}+\frac{c}{a}\right) \\
& =a\left(x^{2}+\frac{b x}{a}+\frac{b^{2}}{4 a^{2}}-\frac{b^{2}}{4 a^{2}}+\frac{c}{a}\right) \\
& =a\left[\left(x^{2}+\frac{b x}{a}+\frac{b^{2}}{4 a^{2}}\right)-\left(\frac{b^{2}}{4 a^{2}}-\frac{c}{a}\right)\right] \\
& =a\left[\left(x+\frac{b}{2 a}\right)^{2}-\left(\frac{\left(b^{2}-4 a c\right)}{4 a^{2}}\right)\right]
\end{aligned}
$$

O termo $b^{2}-4 a c$ recebe o nome de discriminante do trinômio do segundo grau, e é representado pela letra grega delta $(\Delta)$. Logo, pode-se escrever:

$$
f(x)=a\left[\left(x+\frac{b}{2 a}\right)^{2}-\left(\frac{\Delta}{4 a^{2}}\right)\right]
$$

Observe que o termo $\left(x+\frac{b}{2 a}\right)^{2} \geq 0$ para todo $x$ real. Já o termo $\frac{(-\Delta)}{4 a^{2}}$ é constante. Além dessas considerações, a diferença é mínima quando tem-se $\left(x+\frac{b}{2 a}\right)^{2}=0 \rightarrow$ $x=\frac{(-b)}{2 a}$. Neste ponto, se $a>0, f(x)$ também assume seu valor mínimo. Portanto, o menor valor assumido pela função $f(x)=a x^{2}+b x+c$ é $f\left(\frac{-b}{2 a}\right)=\frac{-\Delta}{4 a}$. Neste caso, $f(x)$ não assume valor máximo, pois a função é ilimitada superiormente. Analogamente, quando $a<0$, a função $f(x)=a x^{2}+b x+c$ assume valor máximo em $x=\frac{-b}{2 a}$ e não tem valor mínimo, pois é ilimitada inferiormente. 


\subsection{Aplicações}

Muitos problemas envolvendo máximos e mínimos se resolvem fazendo uso da função quadrática. Essa função é bastante familiar aos alunos da Educação Básica. Logo, é importante mencioná-la neste trabalho. A seguir serão resolvidos alguns problemas usando tal função.

Problema 5.1. Mostre que entre todos os retângulos de perímetro $\mathrm{P}$, o de área máxima é o quadrado.

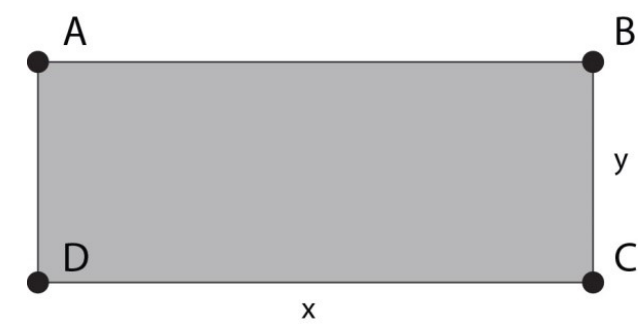

Figura 5.1: Retângulo de lados x e y

Solução: $\mathrm{O}$ perímetro do retângulo é $P=2 x+2 y$ e sua área é dada por $x \cdot y$. Mas, $2 x+2 y=P \rightarrow y=\frac{C-2 x}{2}$. Substituindo esse valor na área, $A_{R}=x \cdot y \Longrightarrow$ $A_{R}=x \cdot\left(\frac{(C-2 x)}{2}\right) \Longrightarrow A_{R}=-x^{2}+\frac{C x}{2}$.

Agora se tem a área em função de $x$, visto que $P$ é fixo, que atingirá o valor máximo, no vértice, então, $x_{v}=\frac{(-b)}{2 a} \Longrightarrow x_{v}=\frac{-\frac{P}{2}}{(2 \cdot(-1))} \Longrightarrow x_{v}=\frac{P}{4}$ Substituindo o valor de $x$, acha-se $y$,

$$
y=\frac{(P-2 x)}{2} \Longrightarrow y=\frac{P-2\left(\frac{P}{4}\right)}{2}=\frac{P}{4}
$$

Portanto, a área será máxima quando $x=y=\frac{p}{4}$, ou seja, quando for um quadrado.

Problema 5.2 Encontre as dimensões de um retângulo $P Q R S$ inscrito num círculo de raio $r$ que nos dão a maior área possível.

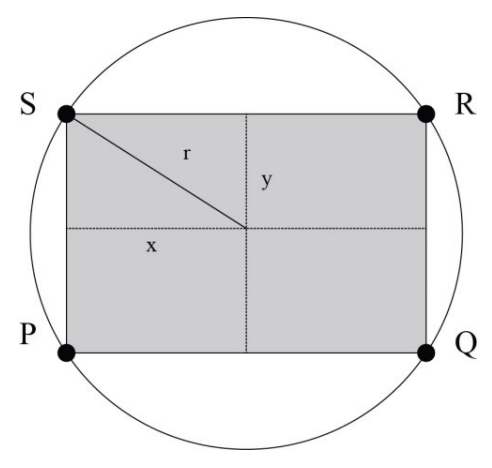

Figura 5.2: Retângulo Inscrito 
Solução: Analisando a Figura 5.2, vê-se que, a área do retângulo é dada por $A_{R}=2 x \cdot 2 y=4 x y$.

Aplicando o teorema de Pitágoras no triângulo de lados $x, y$ e $r$, e tem-se:

$$
r^{2}=x^{2}+y^{2} \Longrightarrow y=\sqrt{r^{2}-x^{2}}
$$

Agora, substituindo o valor de y encontrado na equação da área, tem-se a área em função da variável $x$, visto que $r$ é fixo. Sendo assim,

$$
A_{R}=4 x \sqrt{r^{2}-x^{2}} \Longrightarrow A_{R}^{2}=16 x^{2}\left(r^{2}-x^{2}\right)
$$

Fazendo a substituição $z=x^{2}$ tem-se $A_{R}^{2}=16 z\left(r^{2}-z\right) \Longrightarrow A_{R}^{2}=-16 z^{2}+16 r^{2} z$, o que ainda pode ser escrito

$$
f(z)=-16 z^{2}+16 r^{2} z
$$

Neste caso temos uma função quadrática onde $a=-16<0$. Portanto a função assume o valor máximo em

$$
z_{V}=\frac{-b}{2 a} \Longrightarrow z_{v}=\frac{-16 r^{2}}{2 \cdot(-16)}=\frac{r^{2}}{2}
$$

Substituindo $z_{v}$ na igualdade $z=x^{2}$ tem-se

$$
z=x^{2} \Longrightarrow \frac{r^{2}}{2}=x^{2} \Longrightarrow x=\frac{r}{\sqrt{2}} .
$$

Substituindo o valor de $x$, encontra-se:

$$
y=\sqrt{r^{2}-\left(\frac{r}{\sqrt{2}}\right)^{2}}=\frac{r}{\sqrt{2}}
$$

Portanto, a área do retângulo $P Q R S$ será máxima quando $x=y=\frac{r}{\sqrt{2}}$, ou seja, quando tiver um quadrado. 


\section{Capítulo 6}

\section{Problemas de Otimização que Recaem em uma Função Quadrática}

Encontrar máximos e mínimos de funções é uma das principais aplicações do Cálculo Diferencial. Os chamados "Problemas de Otimização" consistem em encontrar uma função que representa o modelo matemático de uma determinada situação e, de acordo com o que se busca, encontrar os valores de máximo ou mínimo dessa função. No capítulo a seguir, verificaremos exemplos de Problemas de Otimização cujos modelos matemáticos são funções polinomiais do $2^{\circ}$ grau. Encontrar o ponto no qual a função assume seu valor mínimo ou máximo possibilita a obtenção da solução de uma gama de problemas dessa natureza.

Problema 6.1: Um fazendeiro deseja circundar, com 150 metros de cerca, uma área retangular junto a um rio para confinar alguns animais, conforme representado na figura 6.1. Se o objetivo é cercar a maior área possível, quais devem ser as medidas do retângulo ?

Solução: Denominando a largura da área cercada de $x$ e o comprimento de $y$, notamos que $2 x+y=150$ (1), já que é essa a quantidade disponível de cerca. Como a área de um retângulo é calculada pelo produto das medidas do comprimento e da largura, teremos

$$
A=x \cdot y(2) \text {. }
$$

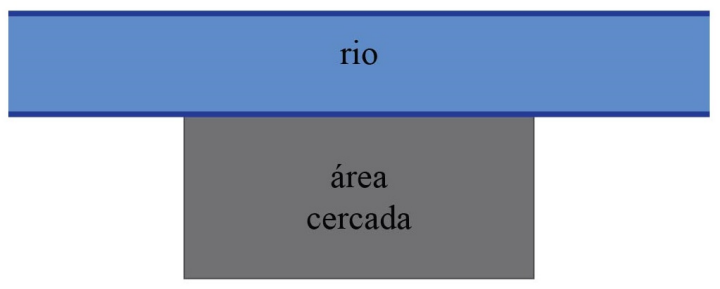

Figura 6.1: Figura ilustrando a situação apresentada no problema 6.1. 
De (1) temos que $y=150-2 x$ e substituindo em (2) teremos

$$
A(x)=x(150-2 x) \Longrightarrow A(x)=150 x-2 x^{2},
$$

ou seja, uma função quadrática, cujo gráfico é uma parábola de concavidade voltada para baixo. Sendo assim, apresenta ponto de máximo.

Como $x_{v}=\frac{-b}{2 a}$, teremos $x_{v}=\frac{-150}{2(-2)}=37,5$. Assim como $y=150-2 x \Longrightarrow$ $y=150-2 \cdot 37,5=75$. Portanto as dimensões que fazem com que seja máxima a área desse retângulo são $75 m$ de comprimento por $37,5 m$ de largura.

Problema 6.2: Um cliente propôs a um vidraceiro que se recorte um espelho retangular com a maior área possível a partir de um pedaço de espelho, cuja forma é de um triângulo retângulo de lados $48 \mathrm{~cm}, 64 \mathrm{~cm}$ e $80 \mathrm{~cm}$. A fim de minimizar a quantidade de cortes, pelo menos um dos lados do retângulo deve estar sobre um lado do triangulo. As posições sugeridas são as da figura 6.2.
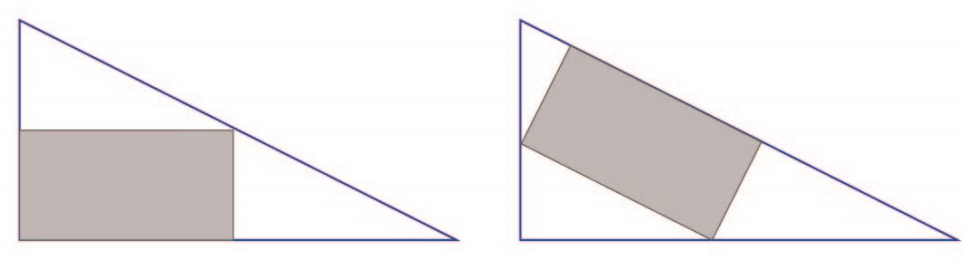

Figura 6.2: Figura ilustrando a situação apresentada no problema 2.

Em cada caso, determinaremos qual o retângulo de maior área e fazer a comparação dos dois resultados.

Solução: i) Primeiramente nomearemos alguns pontos, como ilustrado na figura 6.3:

De acordo com o enunciado temos $A C=48 \mathrm{~cm}, A E=80 \mathrm{~cm}$ e $C E=64 \mathrm{~cm}$. Sejam $C D=y$ e $D F=x$. Note que os triângulos $A B F$ e $F D E$ são semelhantes, logo:

$$
\frac{48-x}{x}=\frac{y}{64-y}
$$

o que implica que

$$
y=-\frac{4}{3} x+64
$$

A área do retângulo $B C D F$ será:

$$
A_{B C D F}=x \cdot y \Longrightarrow A(x)=x \cdot\left(-\frac{4}{3} x+64\right) \Longrightarrow A(x)=-\frac{4}{3} x^{2}+64 x .
$$




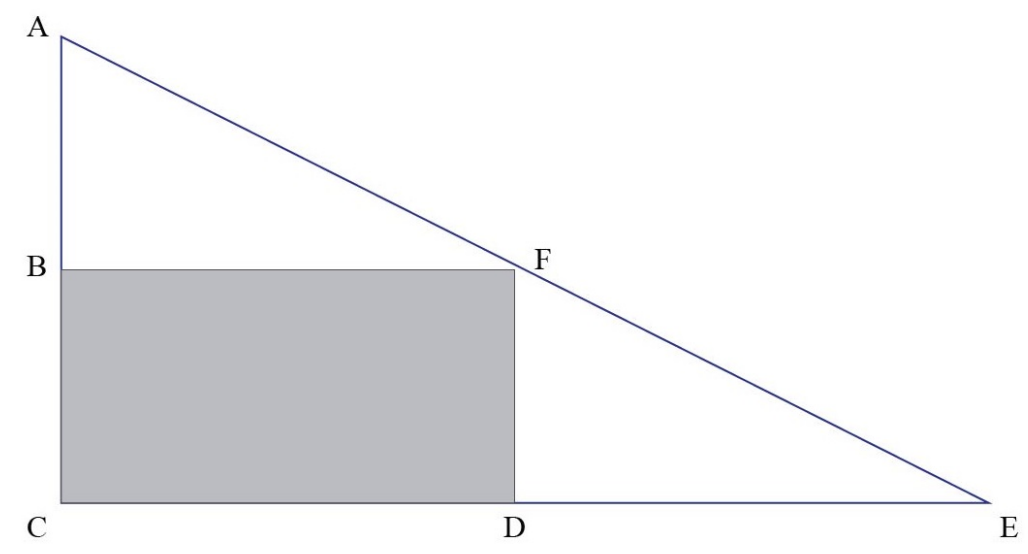

Figura 6.3: Figura ilustrando a situação apresentada no problema 6.2 (i).

O resultado encontrado foi uma função quadrática que, como o gráfico é uma parábola de concavidade voltada para baixo, possui um ponto de máximo. Essa área será máxima se:

$$
x=\frac{-b}{2 a} \Longrightarrow x=\frac{-64}{2 \cdot\left(-\frac{4}{3}\right)} \Longrightarrow x=24 \mathrm{~cm}
$$

Calculando o valor de y teremos:

$$
y=-\frac{4}{3}(24)+64 \Longrightarrow y=32 \mathrm{~cm}
$$

Com esses resultados a conclusão é que para se obter a maior área desse espelho, o retângulo a ser cortado deve ter dimensões de $24 \mathrm{~cm}$ de largura por $32 \mathrm{~cm}$ de comprimento, resultando na área máxima de $768 \mathrm{~cm}^{2}$.

ii) Analogamente a i, vamos nomear alguns pontos, como ilustrado na figura 5:4:

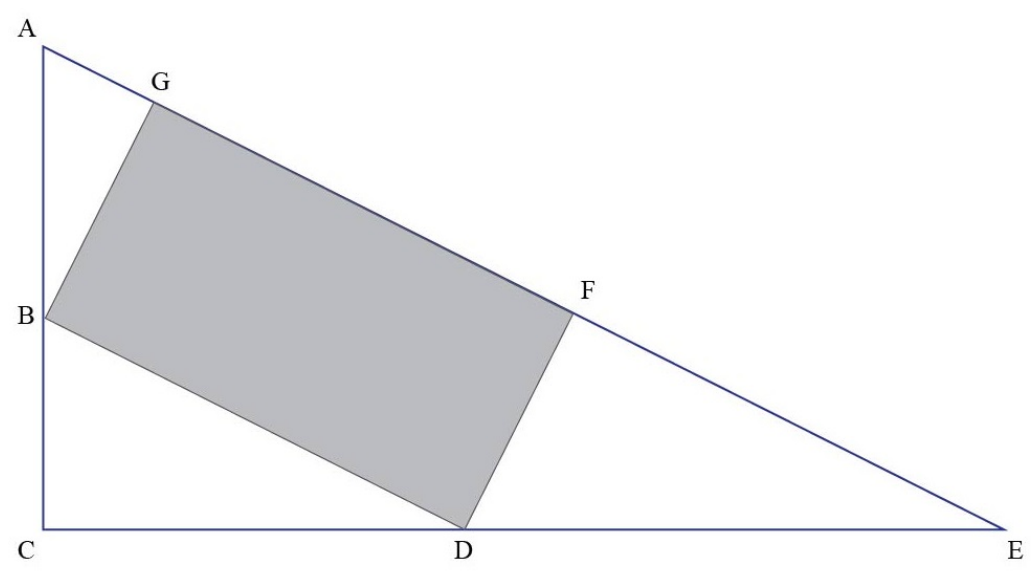

Figura 6.4: Figura ilustrando a situação apresentada no problema 2 (ii). 
Pelo o enunciado temos $A C=48 \mathrm{~cm}, A E=80 \mathrm{~cm}$ e $C E=64 \mathrm{~cm}$. Sejam $B D=x$ e $D F=y$. É possível calcular a altura $h$ relativa a hipotenusa $A E$ do triangulo retângulo $A C E$, usando a fórmula "cateto cateto $=$ hipotenusa $\cdot$ altura", então: $48 \cdot 64=h \cdot 80$ $\Longrightarrow h=38,4 \mathrm{~cm}$.

Note que a altura do triângulo $B C D$, relativa a hipotenusa $B D$, será $38,4-y$. Como os triângulos $B C D$ e $A C E$ são semelhantes, temos que:

$$
\frac{x}{80}=\frac{38,4-y}{38,4}
$$

implicando em

$$
y=\frac{3072-38,4 x}{80}
$$

A área do retângulo $B D F G$ será:

$$
A_{B D F G}=x \cdot y \Longrightarrow A(x)=x \cdot \frac{3072-38,4 x}{80} \Longrightarrow A(x)=-\frac{38,4 x^{2}}{80}+38,4 x .
$$

O resultado é uma função quadrática, cujo gráfico é uma parábola de concavidade voltada para baixo e por consequência possui um ponto de máximo. Assim, a área será máxima se:

$$
x=\frac{-b}{2 a}=-\frac{38,4}{2 \cdot\left(-\frac{38,4}{80}\right)} \Longrightarrow x=40 \mathrm{~cm}
$$

Calculando o valor de $y$ teremos:

$$
y=\frac{3072-38,4 \cdot 40}{80} \Longrightarrow y=19,2 \mathrm{~cm}
$$

Com esses resultados, a conclusão é que para se obter a maior área possível desse espelho, o retângulo a ser cortado deve ter dimensões de $19,2 \mathrm{~cm}$ de largura por $40 \mathrm{~cm}$ de comprimento. A área máxima será também de $768 \mathrm{~cm}^{2}$.

Ao compararmos os dois resultados, observamos que os retângulos obtidos tem a mesma área, $768 \mathrm{~cm}^{2}$. Entretanto, no caso (i) sobram apenas dois pedaços do espelho, enquanto que no caso (ii) restam três pedaços, estes com áreas menores do que os pedaços restantes do caso (i). Outro ponto a se observar é que as dimensões obtidas foram diferentes nos 2 casos e sendo assim, a escolha entre eles vai depender do uso que será dado ao espelho, ou às sobras do espelho original.

Problema 6.3: Um grupo de turistas fretou um avião de 100 lugares para uma excursão. Foi exigido de cada passageiro uma cota de $\mathrm{R} \$ 900,00$ mais $\mathrm{R} \$ 10,00$ por cada lugar vago. Qual a quantidade de passageiros para que a rentabilidade da empresa seja máxima? 
Solução: Supondo que $x$ lugares foram ocupados, teremos vagos $(100-x)$ lugares. Denominando por $R(x)$ a rentabilidade da companhia, teremos que

$$
R(x)=(900+(100-x) \cdot 10) \cdot x \Longrightarrow R(x)=-10 x^{2}+1900 x
$$

que é uma função quadrática cuja concavidade é voltada para baixo. Sendo assim, possui um ponto de máximo. A quantidade de passageiros que maximiza a rentabilidade da companhia será dada por

$$
x_{v}=\frac{-b}{2 a} \Longrightarrow x_{v}=\frac{-1900}{2 \cdot(-10)}=95
$$

Logo, a companhia terá a maior rentabilidade com 95 passageiros.

Problema 6.4: Israel tem uma fábrica de sandálias e vende uma média mensal de 400 unidades, por $\mathrm{R} \$ 20,00$ cada. Contudo, percebeu que a cada vez que diminuía $\mathrm{R} \$ 1,00$ no preço unitário, vendia 40 sandálias a mais. Qual deve ser o preço da unidade de modo que sua receita seja máxima?

Solução: Seja $x$ o desconto de $\mathrm{R} \$ 1,00$ dado. Assim, sua receita em função de $x$ seria: $R(x)=(400+40 x) \cdot(20-1 \cdot x) \Longrightarrow R(x)=-40 x^{2}+400 x+8000$.

Como se trata de uma função quadrática, notamos que a concavidade da parábola que a representa é voltada para baixo e assim possui um ponto de máximo, dado por:

$$
x_{v}=\frac{-b}{2 a}=>x_{v}=\frac{-400}{2 \cdot(-40)}=5
$$

Portanto para que a receita de Israel seja máxima, o desconto por sandália deve ser de $\mathrm{R} \$ 5,00$. Com isso ele deverá cobrar $\mathrm{R} \$ 15,00$ por unidade para maximizar sua receita.

Problema 6.5: Uma granja está fazendo uma promoção na venda de ovos: "Compre $x$ ovos e ganhe $x \%$ de desconto". A promoção é válida para compras de até 5 dúzias, caso em que é concedido o desconto máximo de 60\%. Amanda, Bernardo, Cecília e Douglas compraram 1, 2, 3 e 4 dúzias de ovos, respectivamente. Qual deles poderia ter comprado mais ovos e gasto a mesma quantia?

Solução: Seja $p$ o preço de cada ovo. Logo, com desconto de $x \%$ o preço pago ao comprar $x$ ovos recebendo o desconto de $x \%$ será:

$$
P(x)=p x-\left(\frac{x}{100}\right) \cdot p x=p x \cdot\left(1-\frac{x}{100}\right) \Longrightarrow P(x)=-\frac{p}{100} x^{2}+p x
$$

Note que o maior preço será alcançado para a seguinte quantidade de ovos:

$$
x_{v}=\frac{-b}{2 a}=>x_{v}=\frac{-p}{2 \cdot\left(-\frac{p}{100}\right)}=50
$$

Note que como 40 e 60 são equidistantes de 50, quem por ventura comprar 40 ovos 
vai pagar o mesmo de quem comprar 60. Do mesmo modo notamos que 48 e 52 são equidistantes de 50, logo Douglas que comprou 4 dúzias de ovos poderia ter comprado 4 ovos a mais que pagaria o mesmo valor.

Problema 6.6: O dono de um pequeno teatro percebeu que, com o ingresso a $\mathrm{R} \$$ 8,00, em média 320 pessoas assistem aos espetáculos e que, para cada redução de $\mathrm{R} \$ 1,00$ no preço dos ingressos, o público aumenta de 100 espectadores. Qual deve ser o preço do ingresso para maximizar a receita ?

Solução: Seja $x$ a redução no preço do ingresso, então a receita será dada por:

$R(x)=(320+100 x) \cdot(8-x) \Longrightarrow R(x)=-100 x^{2}+480 x+2560$.

Como se trata de uma função quadrática, a concavidade da parábola é voltada para baixo e assim teremos um ponto de máximo. Logo, a receita será maximizada se o desconto $x$ for:

$$
x_{v}=\frac{-b}{2 a} \Longrightarrow x_{v}=\frac{-480}{2 \cdot(-100)}=2,4
$$

Ou seja, a receita será máxima quando o desconto for de $\mathrm{R} \$ 2,40$. Sendo assim o ingresso deverá custar $\mathrm{R} \$ 5,60$.

Problema 6.7: Um restaurante a quilo vende $100 \mathrm{~kg}$ de comida por dia, a $\mathrm{R} \$ 16,00$ por quilo. Uma pesquisa encomendada pelo dono do estabelecimento revelou que, por cada real de aumento no preço, o restaurante perderia 10 clientes. Sabendo que o consumo médio de cada cliente é de $500 \mathrm{~g}$, qual deve ser o valor do quilo de comida para maximizar a receita diária do restaurante?

Solução: Estimando o número médio de refeições servidas, se o restaurante vende $100 \mathrm{~kg}$ de comida por dia e cada cliente consome, em média, 500g, a média diária de refeições servidas é: $\frac{100}{0,5}=200$ refeições.

Seja x o valor acrescentado ao preço do quilo. Sendo assim, a receita diária do restaurante será:

$$
R(x)=(200-10 x) \cdot(16+x) \Longrightarrow R(x)=-10 x^{2}+40 x+3200 .
$$

Percebendo que se trata de uma função quadrática, cuja concavidade da parábola é voltada para baixo, teremos um ponto de máximo. Com isso, o valor do acréscimo que maximiza a receita será:

$$
x_{v}=\frac{-b}{2 a} \Longrightarrow x_{v}=\frac{-40}{2 \cdot(-10)}=2
$$

Logo, para que a receita seja máxima, o restaurante deve cobrar $\mathrm{R} \$ 16,00+\mathrm{R} \$ 2,00$. Ou seja, R\$18,00 o quilo.

Problema 6.8: Um imóvel, de forma retangular, será construído com lados proporcionais a 3 e 4 . O imposto predial é de $\mathrm{R} \$ 7,00 / \mathrm{m}^{2}$, mais uma taxa fixa de $\mathrm{R} \$ 2500$. 
A prefeitura concede um desconto de $R \$ 60,00$ por metro linear do perímetro, como recompensa pela iluminação externa e pela calçada em volta do prédio. Quais devem ser as medidas dos lados do prédio para que o imposto seja o mínimo possível ? Qual o valor desse imposto mínimo?

Solução: Como os lados da construção devem ser proporcionais a 3 e 4, definiremos os lados como $3 x$ e $4 x$. Com isso a área será dada por $A(x)=12 x^{2}$ e o perímetro será dado por $P(x)=14 x$. Assim sendo, a expressão que calcula o imposto é:

$$
I(x)=2500+7(3 x \cdot 4 x)-60 \cdot(14 x) \Longrightarrow I(x)=84 x^{2}-840 x+2500 .
$$

Vemos que nesse caso se trata de uma função quadrática, com a concavidade da parábola voltada para cima, possuindo assim um ponto de mínimo, que será:

$$
x_{v}=\frac{-b}{2 a} \Longrightarrow x_{v}=\frac{-(-840)}{2 \cdot(84)}=5
$$

Portanto para que o imposto seja o mínimo possível, as medidas dos lados do prédio devem ser $3 \cdot 5=15 \mathrm{~m}$ e $4 \cdot 5=20 \mathrm{~m}$. Cálculo do imposto:

$$
I(5)=84 \cdot 5^{2}-840 \cdot 5+2500 \Longrightarrow I(5)=400 .
$$

Então o valor desse imposto será $\mathrm{R} \$ 400,00$.

Problema 6.9: Considerando 2 números cuja soma é constante, qual o valor máximo do produto desses números ?

Solução: Sendo "s" a constante que representa a soma dos números $x$ e $y$, pretendese achar os valores tais que o produto $x \cdot y$ seja o maior possível. De $x+y=s$ obtemos $y=s-x$ e, portanto, devemos encontrar o valor de $x$ que maximiza o produto $x \cdot(s-x)=-x^{2}+s x$. Esse valor máximo é assumido quando

$$
x=\frac{-b}{2 \cdot a}=\frac{-s}{2 \cdot(-1)}=\frac{s}{2} .
$$

Logo, $y=s-\frac{s}{2}=\frac{s}{2}$.

Assim, pode-se concluir que o produto de dois números cuja soma é constante assume seu valor máximo quando esses números são iguais.

Problema 6.10: A trajetória de uma bola de futebol, num chute a gol, descreve uma parábola. Suponha que, " $t$ " segundos após o chute, sua altura " $h$ ", seja dada, em metros, por $h=-t^{2}+5 t$. Determinaremos em que instante a bola atinge a altura máxima e qual é essa altura máxima.

Solução: Como o gráfico se trata de uma parábola com concavidade voltada para baixo, a função assume um ponto de máximo, quando: 


$$
t_{v}=\frac{-b}{2 a} \Longrightarrow t_{v}=\frac{-5}{2 \cdot(-1)}=2,5
$$

Logo, a bola atinge a altura máxima 2,5 segundos após o chute.

Calculando a altura $h$ máxima atingida pela bola:

$$
h_{v}=\frac{-\Delta}{4 a} \Longrightarrow h_{v}=\frac{-\left(5^{2}-4 \cdot(-1) \cdot 0\right)}{4 \cdot(-1)}=\frac{-25}{-4}=6,25
$$




\section{Capítulo 7}

\section{Problemas de Otimização Resolvidos com o Uso de Derivadas}

Problema 7.1. Deseja-se construir uma caixa, no formato de um bloco reto retangular, utilizando uma folha de papelão, cujas dimensões são $40 \mathrm{~cm}$ por $30 \mathrm{~cm}$. Para isso, retira-se 4 quadrados de lado $x$ (em centímetros), um em cada canto da folha e dobra-se os lados adequadamente obtendo a caixa. Desprezando a espessura da folha, determine a medida $\mathrm{x}$ do lado dos quadrados a serem retirados para que se maximize o volume dessa caixa.

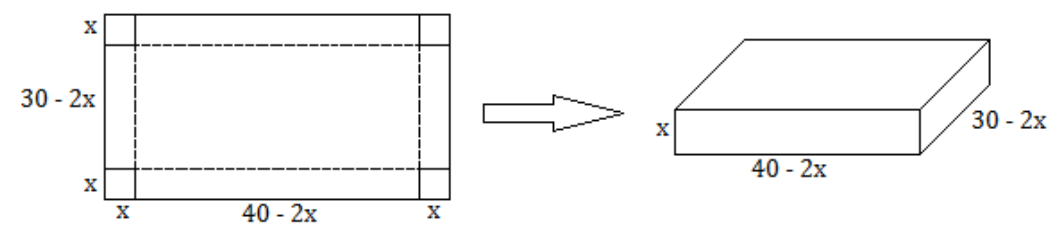

Figura 7.1: problema 1

Solução: Como o lado do quadrado a ser recortado mede $x$, pode-se dizer que a base da caixa é um retângulo cujos lados são $40-2 x$ e $30-2 x$ e a altura mede $x$. Queremos encontrar o valor de $x$ para que o volume $V$ da caixa seja maximizado. A partir das informações sobre as dimensões da caixa em função da variável $x$, temos:

$$
V(x)=x \cdot(40-2 x) \cdot(30-2 x)=4 x^{3}-140 x^{2}+1200 x .
$$

Observe que $0<2 x<30$, ou seja, $0<x<15$. Para determinar os pontos críticos determinemos valores de $x$ para $V^{\prime}(x)=0$.

Igualando a derivada $V^{\prime}(x)=12 x^{2}-280 x+1200$ a zero, obtemos, $x_{1} \approx 17,67 \mathrm{e}$ $x_{2} \approx 5,65$.

O valor $x_{1}$ não faz parte do intervalo $0<x<15$ e, desse modo, não pode ser dimensão do quadrado a ser recortado. 
Aplicando o valor $x_{2}=5,65$ na segunda derivada $V^{\prime \prime}(x)=24 x^{2}-280$, tem-se: $V^{\prime \prime}(5,65)=-144,16<0$. Logo, conclui-se que $x_{2}=5,65 \mathrm{~cm}$ é a medida do lado do quadrado a ser recortado que torna máximo o volume da caixa. Este volume é então: $V(5,65)=4 \cdot 5,65^{3}-140 \cdot 5,65^{2}+1200 \cdot 5,65=3032,30 \mathrm{~cm}^{3}$.

Problema 7.2. Uma fábrica vende bolas de futebol por $\mathrm{R} \$ 50,00$ a unidade. Se a produção mensal dessa fábrica é $x$, em milhares de unidades produzidas e é sabido que o custo total da produção mensal é dado por:

$$
C(x)=\frac{4}{3} x^{3}-30 x^{2}-350 x-100 .
$$

Então, qual é a quantidade de bolas produzidas por mês para que a fábrica tenha um lucro máximo ?

Solução: Sabemos que Lucro é a diferença entre a receita e o custo. Considerando a receita $R(x)=50 x$, consequentemente temos a função Lucro:

$$
L(x)=50 x-\left(\frac{4}{3} x^{3}-30 x^{2}-350 x-100\right)=-\frac{4}{3} x^{3}+30 x^{2}+400 x+100 .
$$

Utilizando o teste da derivada primeira temos:

$$
L^{\prime}(x)=-4 x^{2}+60 x+400
$$

Igualando $L^{\prime}(x)$ a zero, verifica-se que os pontos críticos encontrados são: $x_{1}=-5$ e $x_{2}=20$. Analisando os intervalos de crescimento e decrescimento, temos que $x_{2}=20$ é o ponto que maximiza a função $L$. Por outro lado, podemos encontrar a mesma resposta usando o teste da derivada segunda. Assim, $L^{\prime \prime}(x)=-8 x+60$. Como $L^{\prime \prime}(20)<0$ segue que o ponto crítico $x_{2}=20$ maximiza a função. Portanto, devem ser produzidas 20 mil bolas por mês para que a fábrica obtenha o lucro máximo.

Problema 7.3. Uma cidade é atingida por uma moléstia epidêmica. Os setores de saúde calculam que o número de pessoas atingidas pela moléstia depois de um tempo t (medido em dias a partir do início da epidemia) é dado, aproximadamente, por: $f(t)=64 t-\frac{t^{3}}{3}$

Quando a epidemia estará sob controle?

Solução: A taxa de propagação da epidemia é dada pela variação da função $f(t)$ em relação a $t$. Derivando $f$, temos:

$$
f^{\prime}(t)=64-t^{2}
$$

Assim, para a situação em que a epidemia esteja controlada, sua taxa de expansão deve ser nula. Logo, igualando $f^{\prime}(t)$ a zero, temos: $f^{\prime}(t)=0 \Longrightarrow 64-t^{2}=0 \Longrightarrow$ $t= \pm 8$

Ou seja, após 8 dias, a taxa de expansão da epidemia se anula, logo ela estará 
controlada.

Problema 7.4. O custo mensal de fabricação de uma unidade de fita veda rosca em função do preço unitário de venda $x$, em Reais, é dado por $C(x)=\frac{x^{3}}{3}-2 x^{2}+10 x+1$ e a demanda mensal $p$, do mesmo produto, é dada por $p(x)=10-x$. Qual o preço que deve ser cobrado para maximizar o lucro nessa situação ?

Solução: O lucro total é dado por $\operatorname{Lucro}(L)=\operatorname{Receita}(R)-$ Custo $(C)$. A Receita será calculada por:

$$
R(x)=x(10-x)
$$

Logo, $L(x)=10 x-x^{2}-\left(\frac{x^{3}}{3}-2 x^{2}+10 x+1\right) \Longrightarrow L(x)=-\frac{x^{3}}{3}+x^{2}+1$

Derivando a função Lucro temos:

$$
L^{\prime}(x)=-x^{2}+2 x
$$

Igualando $L^{\prime}(x)$ a zero, encontra-se as raízes $x_{1}=0$ e $x_{2}=2$. Como $L^{\prime \prime}(2)<0$, temos que $x_{2}=2$ é ponto de máximo de $L$. Logo, para maximizar o lucro dessa empresa, o valor de venda do produto deve ser $\mathrm{R} \$ 2,00$.

Problema 7.5. Uma ribeirinha pretende sair de um ponto A na margem de um rio de $1 \mathrm{~km}$ de largura, atravessar o rio de canoa e então, chegar o mais rápido possível correndo pela margem do rio até um ponto $D$ situado a $2 \mathrm{~km}$ de distância da reta que passa pelo ponto $A$ e é perpendicular ao rio. Se ela remar a canoa a $6 \mathrm{~km} / \mathrm{h}$ e correr a $9 \mathrm{~km} / \mathrm{h}$, a que distância de $B$ ela deve terminar a travessia de canoa ?

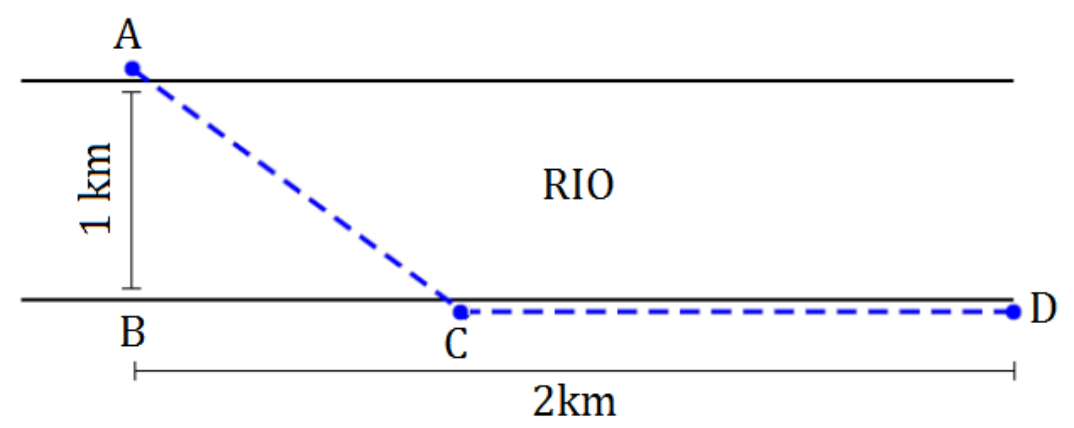

Figura 7.2: Figura ilustrando a situação apresentada no Problema.

Solução: Sabendo que $C$ é o ponto da margem onde a mulher deve terminar a travessia de canoa. Fazendo então $B C=x$, teremos $C D=2-x$. Note que ABC é um triângulo retângulo e, pelo Teorema de Pitágoras, teremos $A C=\sqrt{1+x^{2}}$. Seja $t_{1} \mathrm{o}$ tempo de travessia com a canoa (de $A$ até $C$ ) e $t_{2}$ o tempo gasto para ir correndo de $C$ até $D$. Como a velocidade da canoa é de $6 \mathrm{~km} / \mathrm{h}$, teremos que $t_{1}=\frac{\sqrt{1+x^{2}}}{6}$ e que como a velocidade da corrida é $9 k m / h, t_{2}=\frac{2-x}{9}$. Diante disso, o tempo total do percurso 
será $t=t_{1}+t_{2}$, ou seja, $t(x)=\frac{\sqrt{1+x^{2}}}{6}+\frac{2-x}{9}$. Note que o intervalo [0;2] é o domínio da função para essa situação e que estamos em busca do valor de $x$ desse domínio que minimiza o tempo $t(x)$ para a pessoa sair do ponto $A$ e chegar até o ponto $D$. Para determinar tal valor lançaremos mão do cálculo da derivada de $t(x)$ e assim achar o(s) ponto(s) críticos, verificando através da regra da segunda derivada se é ponto de máximo, mínimo ou inflexão.

A derivada de $t(x)$ é:

$$
t^{\prime}(x)=\frac{3 x-2 \sqrt{x^{2}-1}}{18 \sqrt{x^{2}+1}}
$$

Igualando a zero teremos:

$$
\frac{3 x-2 \sqrt{x^{2}-1}}{18 \sqrt{x^{2}+1}}=0 .
$$

Note que a fração será nula se:

$$
3 x-\sqrt{x^{2}-1}=0 \Longrightarrow 3 x=2 \sqrt{x^{2}-1} .
$$

Elevando ambos membros ao quadrado, teremos:

$$
9 x^{2}=4\left(x^{2}-1\right) \Longrightarrow 9 x^{2}-4 x^{2}=4 \Longrightarrow 5 x^{2}=4 \Longrightarrow x^{2}=\frac{4}{5} \Longrightarrow x= \pm \sqrt{\frac{4}{5}} \text {. }
$$

Como $x$ representa distância, o valor negativo não nos interessa. Temos então que $x=\sqrt{\frac{4}{5}}$ é o único ponto crítico.

Calculando agora a segunda derivada de $t(x)$ teremos:

$$
t^{\prime \prime}(x)=\frac{1}{6\left(x^{2}+1\right) \sqrt{x^{2}+1}} .
$$

Note que " $(x)>0$, para todo $x \in \mathbb{R}, \operatorname{logo} x=\sqrt{\frac{4}{5}}$, cujo valor aproximado é 0,89 , é um ponto de mínimo de $t$. Assim, para chegar o mais rápido possível em $D$, a distância que ela percorrerá correndo pela margem do rio será:

$$
C D=2-\sqrt{\frac{4}{5}} \cong 1,11
$$

Problema 7.6 Uma indústria de óleo precisa desenvolver uma embalagem de 2 litros. Esta embalagem deve ser um cilindro com base circular.

Sabendo que custo por unidade de área do material utilizado no topo e na base é o dobro do custo do material utilizado na lateral do cilindro. 
Quais devem ser as dimensões dessa embalagem de modo a minimizar o custo com o material utilizado ?

Solução: Primeiramente, vamos definir que se trata de um cilindro reto com raio da base medindo $r$ e altura medindo $h$, ambas as dimensões em centímetros.

É necessário relembrar alguns conceitos importantes sobre o cilindro reto a fim de organizarmos nossos cálculos.

1) A área do topo (chamada de $A_{t}$ ) é igual à da base (chamada de $A_{b}$ ), ambas calculadas por:

$$
A_{t}=A_{b}=\pi r^{2}
$$

2) A área lateral (chamada de $A_{l}$ ), cujo formato é retangular, é calculada por:

$$
A_{l}=2 \pi r h
$$

3) Volume do cilindro, calculado por:

$$
V=\pi r^{2} h
$$

Definindo por $C$ o custo da produção do topo e da base temos que o custo da produção da lateral do cilindro é definido por $2 C$, em $R \$ / \mathrm{cm}^{2}$.

Assim sendo, temos que o custo total da produção da base e do topo é dado por:

$$
2 C \cdot\left(\pi r^{2}+\pi r^{2}\right)=4 \pi C r^{2}
$$

E o custo total da produção da lateral é dado por:

$$
C \cdot 2 \pi r^{2} h=2 \pi C r^{2} h(2)
$$

Somando (1) e (2), temos o custo total (T) de produção dessa lata, definido por:

$$
T=4 \pi C r^{2}+2 \pi C r^{2} h
$$

Sabe-se que o volume do cilindro em questão é igual a 2 litros, que é equivalente a $2000 \mathrm{~cm}^{3}$. Logo, podemos dizer que:

$$
V=\pi r^{2} h=2000 \Longrightarrow h=\frac{2000}{\pi r^{2}}
$$

Agora, vamos reescrever a função T em função de r como:

$$
T(r)=4 \pi C r^{2}+2 \pi C r^{2} \cdot \frac{2000}{\pi r^{2}}=4 \pi C\left(r^{2}+\frac{1000}{\pi r}\right)
$$


Como o objetivo é encontrar o valor mínimo do custo, vamos fazer a derivada da função $T(r)$ e em seguida, igualar o resultado à zero

$$
\begin{aligned}
& T^{\prime}(r)=4 \pi C\left(2 r-\frac{1000}{\pi r^{2}}\right) \\
& 4 \pi C\left(2 r-\frac{1000}{\pi r^{2}}\right)=0 \rightarrow 2 r-\frac{1000}{\pi r^{2}}=0 \rightarrow 2 r=\frac{1000}{\pi r^{2}} \rightarrow r=\sqrt[3]{\frac{1000}{2 \pi}} \rightarrow r=\frac{10}{\sqrt[3]{2 \pi}}
\end{aligned}
$$

A partir desse valor de $r$, vamos calcular o valor de $h$.

$$
h=\frac{2000}{\pi r^{2}}=\frac{2000}{\pi \cdot\left(\frac{10}{\sqrt[3]{2 \pi}}\right)^{2}}=\frac{20}{\frac{\pi}{\sqrt[3]{4 \pi^{2}}}}=20 \sqrt[3]{\frac{4}{\pi}}
$$

Considerando o valor aproximado $\pi=3,14$, temos que as dimensões do raio e da altura do cilindro são:

$$
\begin{aligned}
& r=\frac{10}{\sqrt[3]{6,28}} \cong \frac{10}{1,845} \cong 5,42 \mathrm{~cm} \\
& h=20 \sqrt[3]{\frac{4}{3,14}} \cong 20 \cdot 0,405 \cong 8,10 \mathrm{~cm}
\end{aligned}
$$

Logo, para minimizar o custo dessa lata, o raio deve medir aproximadamente 5,42 $\mathrm{cm}$ e a altura deve medir, aproximadamente, $8,10 \mathrm{~cm}$. 


\section{Considerações Finais}

Na primeira metade do século passado, o Cálculo Matemático fazia arte do currículo da educação básica brasileira. Contudo, a partir dos anos 1960 foi sendo excluído gradativamente. Ainda que alguns livros didáticos seguissem destinando algumas de suas seções a esse tema, o mesmo não é discutido em sala de aula no Ensino Médio.

Diante das exigências de cumprir o atual conteúdo e apoiados no fato de que o ensino de Cálculo não é obrigatório, fica cada vez mais difícil que os docentes busquem fazer esse tipo de trabalho. Certos fundamentos do Cálculo, como vimos nesse trabalho, são de grande valia para a formação dos jovens e não são tão complexos que não possam ser abordados no Ensino Médio, no $3^{\circ}$ ano.

Nesta produção defendemos a ideia de tratar os conceitos de derivada de modo a conectá-los com as funções polinomiais e introduzir na educação básica o necessário para construção de gráficos, não somente do $2^{\circ}$ grau e, principalmente, verificar máximos e mínimos. Assim sendo, a abordagem com as questões de otimização se tornariam mais atraentes, visto que neste trabalho priorizamos a ideia de trabalhar os conceitos de derivadas de maneira integrada com os conceitos de funções polinomiais e/ou polinômios e seus respectivos gráficos, pois atualmente no ensino médio os alunos aprendem a esboçar gráfico de polinômios de $2^{\circ}$ grau sem o uso de derivadas e não aprendem como fazer o esboço de gráfico de polinômios de $3^{\circ}$ grau.

Seria extremamente vantajosa a introdução do estudo de derivadas no Ensino Médio. Até porque, se trata de ferramenta de alta utilidade para auxiliar em uma melhor compreensão dos conceitos de crescimento, decrescimento, ponto de inflexão, concavidade de curvas e, primordialmente, verificar os ponto de máximo e mínimo de funções quadráticas e de $3^{\circ}$ grau. Além disso, pode se trabalhar de forma interdisciplinar com a Física, em questões que envolvam cálculos de velocidade e aceleração escalar ou trajetórias parabólicas. Desse modo, os alunos terão um aprendizado mais significativo desses conteúdos e, por conseguinte, serão mais bem sucedidos, ao ingressar no ensino superior, caso lidem com disciplinas que envolvam cálculo.

Portanto, fica a sugestão para os professores da educação básica, em especial os 
do Ensino Médio para que, apesar das imposições dos currículos vigentes e da política de preparação para exames de acesso ao Ensino Superior, repensem a ideia de não abordarem temas de cálculo. Ao invés, que invistam no tema, visto que o mesmo é extremamente enriquecedor para o desenvolvimento das ideias de otimização. É evidente que essa sugestão é apenas um passo diante do longo caminho que levaria para que o tema fosse novamente introduzido no currículo e então trabalhado amplamente nas fileiras escolares do país. 


\section{Referências Bibliográficas}

[1] ÁvILA, Geraldo Severo de Souza, Cálculo das Funções de uma variável. Volume I.7a Edição [reimpressão]. Rio de Janeiro. LTC. 2008.

[2] ÁviLA, Geraldo Severo de Souza, Cálculo 1 : funções de uma variável, 4a edição, Rio de Janeiro: Livros Técnicos e Científicos Editora, 1981.

[3] ÁvilA, Geraldo Severo de Souza. O ensino de Cálculo no $2^{\circ}$ grau. Revista do Professor de Matemática, nº 18, 1991.

[4] ÁVILA, Geraldo Severo de Souza. Limites e derivadas no ensino médio. Revista do Professor de Matemática, no 60, 2006.

[5] BIAnO, Adão de Aguiar. O Esboço de Gráficos de Polinômios de $2^{\circ}$ e $3^{o}$ graus usando Derivadas. Mato Grosso, 2015.

[6] BOYER, Carl Benjamin. História da Matemática. 2a edição. São Paulo: Edgard Blucher, 2003.

[7] BRASIL. Ministério da Educação e Cultura. Parâmetros Curriculares Nacionais para o Ensino médio: Parte III - Ciências da Natureza, Matemática e suas Tecnologias. Brasília, 1999.

[8] BRASIL, Ministério da Educação. Secretaria de Educação Fundamental. Parâmetros Curriculares Nacionais: matemática. Brasília: Ministério da Educação/Secretaria de Educação Fundamental, 1998.

[9] CARvalho, Paulo Cézar Pinto; MOrgado, Augusto Cézar de Oliveira. Matemática discreta: coleção PROFMAT, Rio de Janeiro: SBM, 2014.

[10] DANTE, Luiz Roberto. Matemática: Contexto \& Aplicações - vol. 1. 2a ed. São Paulo: Ática, 2014. 
[11] DANTE, Luiz Roberto. Didática da Resolução de Problemas em Matemática. São Paulo: Ática, 1989.

[12] DISTRITO FEDERAL, Secretaria de Estado de Educação. Currículo em Movimento da Educação Básica - Ensino Médio: documento básico. Distrito Federal: Secretaria de Estado de Educação do Distrito Federal, 2014.

[13] EVES, Howard. Introdução à História da Matemática; tradução Hygino H. Domingues, $5^{\mathrm{a}}$ ed. Campinas: Editora da Unicamp, 2011.

[14] FERREIRA, Márcio do Socorro Costa. Uma Abordagem Didática Para O Ensino De Máximo Ou Mínimo Na Função Quadrática - 2014

[15] IEZZI, Gelson; MURAKAMI, Carlos. Conjuntos e Funções, Fundamentos de Matemática Elementar, 8a Edição, São Paulo: Atual, 2004.

[16] IEZZI, Gelson; DOLCE, Osvaldo; DEGENSZAJN, David; PÉRIGO, Roberto. Matemática - Volume Único. 4a ed. São Paulo: Atual, 2007.

[17] IEZZI, Gelson; MURAKAMI, Carlos; MACHADO, Nilson José. Fundamentos de Matemática Elementar: Limites, Derivadas e Noções de Integral - Vol. 8. 6a ed. São Paulo: Atual, 2005.

[18] LEITHOLD, Louis. O Cálculo com Geometria Analítica - Volume 1, $3^{\text {a }}$ edição, São Paulo : Editora Harbra 1994.

[19] LEITHOLD, Louis. O Cálculo com Geometria Analítica. V.1-2. Ed. Editora Harbra. São Paulo: 1986.

[20] LIMA, Elon Lages. A Matemática do Ensino Médio. Volume 1. Rio de Janeiro: SBM, 2012.

[21] LIMA, Elon Lages. Análise Real: Funções de Uma Variável - Vol. 1. 9a ed. Rio de Janeiro: Coleção Matemática Universitária - IMPA, 2007.

[22] LIMA, Elon Lages. Análise Real: Funções de Uma Variável - Vol. 2. 3a ed. Rio de Janeiro: Coleção Matemática Universitária - IMPA, 2007.

[23] MUNIZ NETO, Antônio Caminha. Fundamentos de cálculo: coleção PROFMAT. Rio de Janeiro: SBM, 2014.

[24] PAIVA, Manoel. Matemática - Volume Único. 1a ed. São Paulo: Moderna, 2005.

[25] POLYA, George. A arte de resolver problemas: um novo aspecto do método matemático; tradução: Heitor Lisboa de Araújo, $2^{\mathrm{a}}$ reimpressão Rio de Janeiro: Interciência, 1995. 
[26] SBM. Fundamentos de Cálculo. Material Disponibilizado ao PROFMAT, 2012.

[27] STEWART, James. Cálculo, Vol. I, 5a Edição, São Paulo: Pioneira Thomson Learning, 2006.

[28] STEWART, James. Cálculo, Volume II, 5a edição, São Paulo: Pioneira Thomson Learning, 2006. 